\title{
Modelling European winter wind storm losses in current and future climate
}

\section{Journal Article}

Author(s):

Schwierz, Cornelia; Köllner-Heck, Pamela; Mutter, Evelyn Zenklusen; Bresch, David N.; Vidale, Pier Luigi; Wild, Martin; Schär, Christoph

\section{Publication date:}

2010-08

\section{Permanent link:}

https://doi.org/10.3929/ethz-b-000156499

Rights / license:

In Copyright - Non-Commercial Use Permitted

Originally published in:

Climatic Change 101(3-4), https://doi.org/10.1007/s10584-009-9712-1 


\title{
Modelling European winter wind storm losses in current and future climate
}

\author{
Cornelia Schwierz • Pamela Köllner-Heck • \\ Evelyn Zenklusen Mutter • David N. Bresch • \\ Pier-Luigi Vidale · Martin Wild • Christoph Schär
}

Received: 12 September 2007 / Accepted: 27 August 2009 / Published online: 25 November 2009

(C) Springer Science + Business Media B.V. 2009

\begin{abstract}
Severe wind storms are one of the major natural hazards in the extratropics and inflict substantial economic damages and even casualties. Insured stormrelated losses depend on (i) the frequency, nature and dynamics of storms, (ii) the vulnerability of the values at risk, (iii) the geographical distribution of these values, and (iv) the particular conditions of the risk transfer. It is thus of great importance to assess the impact of climate change on future storm losses. To this end, the current study employs - to our knowledge for the first time-a coupled approach, using output from high-resolution regional climate model scenarios for the European sector to drive an operational insurance loss model. An ensemble of coupled climatedamage scenarios is used to provide an estimate of the inherent uncertainties. Output of two state-of-the-art global climate models (HadAM3, ECHAM5) is used for
\end{abstract}

C. Schwierz $(\varangle) \cdot$ E. Zenklusen Mutter · P.-L. Vidale · M. Wild · C. Schär Institute for Atmospheric and Climate Science, ETH Zürich, Zürich, Switzerland e-mail: schwierz@stat.math.ethz.ch

P. Köllner-Heck · D. N. Bresch

Swiss Reinsurance Company, Zürich, Switzerland

Present Address:

P. Köllner-Heck

Federal Office for the Environment, Berne, Switzerland

Present Address:

C. Schwierz

Seminar for Statistics, ETH Zürich, Zürich, Switzerland

Present Address:

E. Zenklusen Mutter

WSL Institute for Snow and Avalanche Research SLF, Davos Dorf, Switzerland

Present Address:

P.-L. Vidale

NCAS-Climate, Reading University, Reading, UK 
present (1961-1990) and future climates (2071-2100, SRES A2 scenario). These serve as boundary data for two nested regional climate models with a sophisticated gust parametrization (CLM, CHRM). For validation and calibration purposes, an additional simulation is undertaken with the CHRM driven by the ERA40 reanalysis. The operational insurance model (Swiss Re) uses a European-wide damage function, an average vulnerability curve for all risk types, and contains the actual value distribution of a complete European market portfolio. The coupling between climate and damage models is based on daily maxima of $10 \mathrm{~m}$ gust winds, and the strategy adopted consists of three main steps: (i) development and application of a pragmatic selection criterion to retrieve significant storm events, (ii) generation of a probabilistic event set using a Monte-Carlo approach in the hazard module of the insurance model, and (iii) calibration of the simulated annual expected losses with a historic loss data base. The climate models considered agree regarding an increase in the intensity of extreme storms in a band across central Europe (stretching from southern UK and northern France to Denmark, northern Germany into eastern Europe). This effect increases with event strength, and rare storms show the largest climate change sensitivity, but are also beset with the largest uncertainties. Wind gusts decrease over northern Scandinavia and Southern Europe. Highest intraensemble variability is simulated for Ireland, the UK, the Mediterranean, and parts of Eastern Europe. The resulting changes on European-wide losses over the 110-year period are positive for all layers and all model runs considered and amount to $44 \%$ (annual expected loss), 23\% (10 years loss), 50\% (30 years loss), and 104\% (100 years loss). There is a disproportionate increase in losses for rare high-impact events. The changes result from increases in both severity and frequency of wind gusts. Considerable geographical variability of the expected losses exists, with Denmark and Germany experiencing the largest loss increases (116\% and $114 \%$, respectively). All countries considered except for Ireland (-23\%) experience some loss increases. Some ramifications of these results for the socio-economic sector are discussed, and future avenues for research are highlighted. The technique introduced in this study and its application to realistic market portfolios offer exciting prospects for future research on the impact of climate change that is relevant for policy makers, scientists and economists.

\section{Introduction}

The insured natural catastrophe losses due to atmospheric hazards have increased steadily over the last 30 years. An account of the evolution of annual worldwide weather-related insured natural catastrophe losses is given in Fig. 1a. In the 1970s the mean yearly insured losses amounted to approximately 2-3 billion (bn) USD while in the last couple of years (2001-2006) the average value increased to more than 30 bn USD (all figures in 2006 prices). Potential factors contributing to this rise are found in economic, geographic and demographic sectors and comprise: -increasing assets at risk due to rising population and insurance density, -larger concentrations of values in exposed areas and thus higher degrees of vulnerability. It is widely accepted that the world's climate is changing which results in significant alterations of regional weather and climatic conditions (e.g. IPCC 2001, 2007), and the potential for a climate-change induced increase of atmospheric hazards has been recognized 
(a)

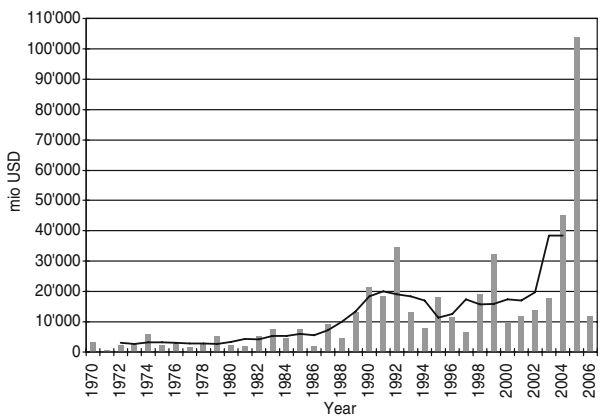

(b)

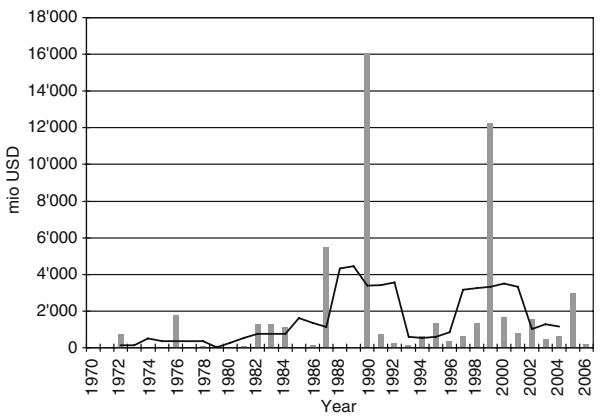

Fig. 1 a Annual worldwide weather-related insured natural catastrophe losses (flood, storm, drought, cold and hail) 1970-2006 (USD mio, prices 2006), b Annual insured windstorm losses for Europe 1970-2006 (USD mio, prices 2006). 5-year-running-averages overlaid (black). Source: Swiss Re sigma Catastrophe database

by the insurance industry for some time, e.g. Berz (1993), Changnon et al. (1997). The degree to which the rise in catastrophe loss can be attributed to climate change has not yet been quantified. Hence, from both a societal and an economic perspective, it is crucial to determine the extent to which changes in a warmer climate could further add to the damage figures.

The focus of this study is on European winter storms. Figure $1 \mathrm{~b}$ is the analogue of Fig. 1a, but for winter storm losses in Europe. These exhibit a much stronger variability (volatility). Since 1970 there have been 70 severe wind storm events resulting in total insured losses of approximately 50 bn USD. The thirteen most severe storm events alone account for nearly 80\% (or 40 bn USD, in 2006 prices) of total insured winter storm losses in this period. The volatility of losses is exacerbated by the clustering of severe storms, with four in 1990, and three in 1999. In 1990, the total insured loss resulting from four winter storms amounted to $14.6 \mathrm{bn}$ USD, caused by Herta (1.3 bn USD), Vivian (4.9 bn USD), Wiebke (1.2 bn USD) and Daria (7.2 bn USD). In 1999, Anatol (2.3 bn USD), Lothar (7.0 bn USD) and Martin (2.9 bn USD) caused an insured loss of 12.2 bn USD (all in 2006 prices).

According to the Swiss Re loss model, an insured storm loss in the order of some 7 bn USD can currently be expected to occur in Europe about once every ten years while one of 30 bn USD is anticipated once every 100 years (see also Fig. 2). Other insurance models yield similar damage-frequency relations. History has shown that winter storms can engender huge losses and insurance models suggest that even higher losses are possible. Most of the operational insurance models are based on historical data. Monte-Carlo-like sampling techniques are then applied to obtain a comprehensive data base (see Section 2.2 for the description of the Swiss Re loss model). For a more realistic risk assessment, especially when taking into account impacts of future climate change, it is highly desirable to link the insurance model with a three-dimensional dynamical climate model. This would allow a more physically-based estimate of current and future annual expected losses and loss potentials to be derived.

The aim of the study is to quantify wind-storm losses on a European-wide property insurance portfolio, under current and future climatic conditions. The study involves 


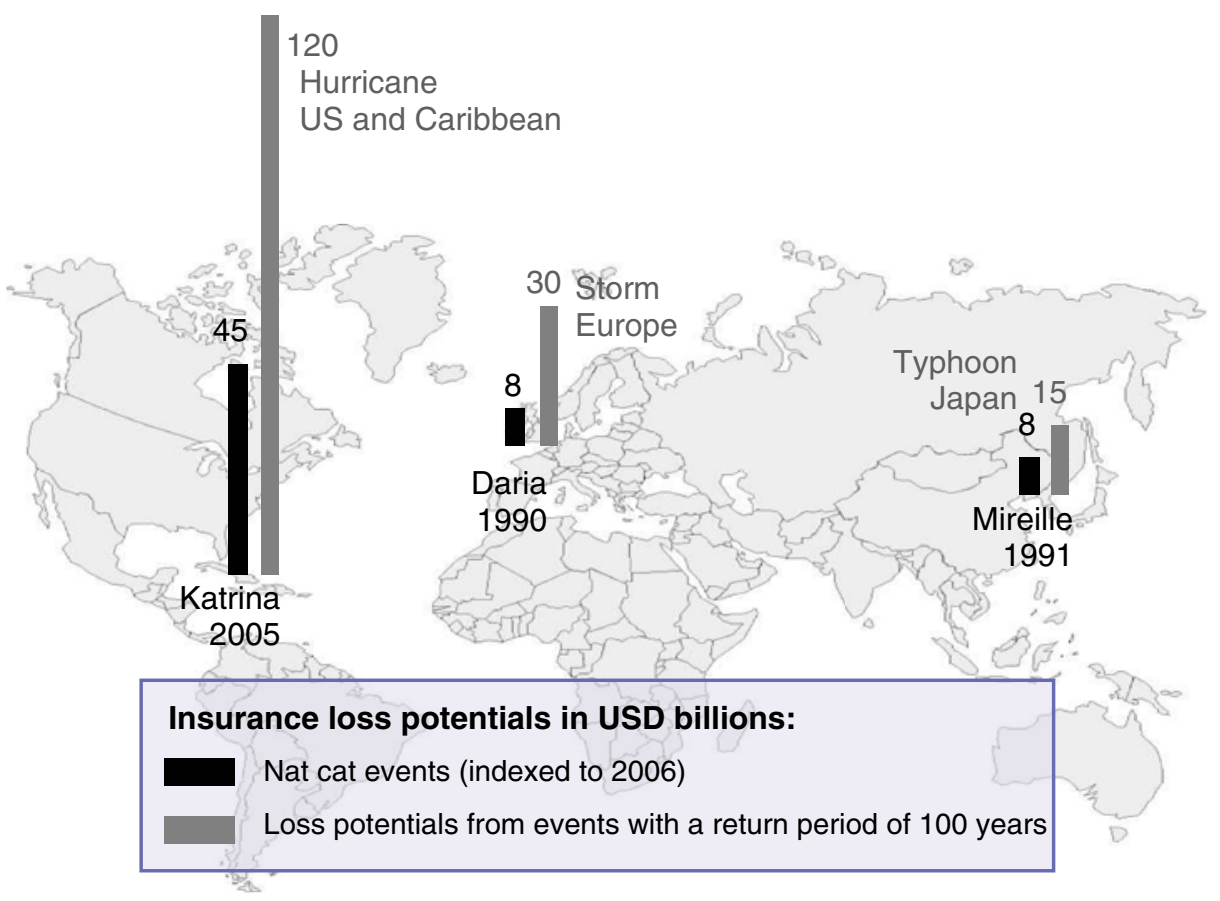

Fig. 2 Insurance loss potentials for weather-related hazards (100 year return period events) and largest historical insured losses (in USD bn, 2006 prices)

two steps: First, using output from a series of climate models, we analyze changes in surface wind speed and in the frequency of heavy windstorm events. Second, using an insurance loss model, we determine the impact of these changes on insurance losses. It is crucial to study both these factors in combination. Increasing losses are not an inevitable consequence of potentially increasing wind intensity and/or frequency in a warmer climate. The loss amount of a particular storm depends on both its path and its absolute force. It is important to determine (i) whether a storm affects a region with a high concentration of values or passes over sparsely populated territory, and (ii) to what extent and within which intervals the wind intensity changes, as small changes in hazard intensity may trigger substantial changes in damages, due to a nonlinear relationship between atmospheric conditions and inflicted damages.

A number of factors will determine the response of mid-latitude cyclone activity and winter storm frequency to global climate change. Some of the key physical issues are: First, the geographic distributions of near-surface temperature and seaice imply pronounced modifications in the low-level temperature contrast (baroclinicity), which in turn affects the strength and location of the storm tracks (Held 1993). As polar regions tend to warm stronger than the tropics, climate change diminishes the overall equator-to-pole surface temperature contrast, suggesting an overall decrease in cyclone activity. However, there is a competing effect as the upper-level baroclinicity may strengthen. In this way characteristic atmospheric circulation patterns such as the North Atlantic Oscillation might also be affected 
(Ulbrich and Christoph 1999). Second, as the atmosphere warms, it also becomes moister. This moistening effect is expected to approximately follow the ClausiusClapeyron relationship, thus suggesting a sizeable moistening of about $6 \%$ per degree warming (DelGenio et al. 1991). A moister atmosphere implies that the equator-to-pole transport of latent heat (water vapor) will increase at the expense of the sensible heat transport (Boer 1995). Similar to the reduced amplitude of the equator-to-pole temperature contrast, this factor thus points towards an overall reduction of cyclone activity. Third, it is important to note that a reduction of mean cyclone activity does not necessarily imply a reduction in the frequency of deep cyclones and associated winter storms. In particular, there is ample evidence from the meteorological literature that atmospheric humidity plays a key role in spinning up extratropical cyclones, e.g. Wernli et al. (2002). This spin-up effect is most effective below the level of maximum condensational heating (Hoskins et al. 1985). The anticipated moistening of the atmosphere might thus favor a low-level strengthening of extratropical cyclones with potential implications on near-surface wind fields and winter storms.

As the aforementioned factors do work in different directions, comprehensive climate simulations are needed to establish the overall response of the atmospheric circulation. A number of such studies, using climate models of increasing sophistication, have been published in recent years. Overall a fairly coherent picture emerges. On a global scale and for the winter seasons, Geng and Sugi (2003), using a highresolution GCM, find a poleward shift of the storm track, an overall reduction in the density of cyclones (number of cyclones per area) by almost $10 \%$, and an increase in the number of strong cyclones. The different trends in the counts of weak/moderate versus strong cyclones are confirmed by several other studies (e.g. Carnell and Senior 1998; Lambert 1995; Knippertz et al. 2000; Pinto et al. 2007), but not in all of the literature (Beersma et al. 1993; Schubert et al. 1998). This partly conflicting information will also be assessed in the current study, as we will employ follow-up versions (HadAM3, ECHAM5) of the models used by Carnell and Senior (1998) (HadAM2), Beersma et al. (1993) (ECHAM3), Schubert et al. (1998) (ECHAM3) and Knippertz et al. (2000) (ECHAM4).

It is important to stress that the changes in cyclone activity strongly depend upon the region under consideration. In terms of a regional assessment, a more detailed analysis is needed. Several studies have used high-resolution GCMs and/or limitedarea RCMs to focus upon changes in specific areas. Regarding the North Atlantic / European sector, Leckebusch and Ulbrich (2004) and Leckebusch et al. (2006) find an increase in the track density of strong cyclones over western parts of Central Europe. This increase occurs for the IPCC A2 greenhouse gas scenario, but is much less pronounced for the B2 scenario. Consistent with these results, Rockel and Woth (2007) find an increase of storm peak events by up to $20 \%$ over Central Europe within the next 100 years. As a result, an increase in the frequency of storm surges is expected (Woth et al. 2006). The latter increase was simulated using a storm surge model driven by RCMs, and it occurs for most of the North Sea coast with the exception of the East coast of the UK, and for all four RCMs considered.

These extensive results derived in the climate community have yet to find their full application within the modelling approaches of the insurance sector. Watson and Johnson (2004) provide a comprehensive review on insurance loss models and the existing range of their sub-components. They point out that virtually all of the 
wind models in use are parametric models with simple storm parameters, and that the application of climate models had so far not been used operationally due to the computational complexity. However, in a sensitivity study with a representative state-of-the art insurance-type model, they show (for hurricanes) that minor changes in the wind model input parameters (e.g. background surface pressure) can result in significant impacts on the computed loss. They therefore conclude that uncertainties in the wind field propagate dramatically into the damage calculations. A significant improvement can thus be expected with the use of more realistic wind data.

Some studies estimate loss potentials from the available climate model data, e.g. Klawa and Ulbrich (2003), Leckebusch et al. (2007), Pinto et al. (2007). They are based on an approach derived by Klawa and Ulbrich (2003): a loss index is computed based on the excess of wind speed over the upper $2 \%$ quantile, and which depends on population numbers in the individual districts within Germany. The calibration is undertaken against publicly available insurance loss data over Germany, which is then applied to other European regions by the later studies. However no operational insurance loss model is utilized in any of these studies.

The present study is one of the first to couple the output from state-of-theart regional climate models to a slightly modified version of an operational insurance loss model. This interdisciplinary approach combines both meteorological and insurance aspects of storms. Consistent with the occurrence of damaging winter storms in Europe, we focus on an extended winter season. In accordance with Swiss Re procedures, this winter season is here defined as October through to March (Oct-Mar).

\section{Data and models}

\subsection{Meteorological data and models}

The climate model data utilized in this study has been obtained using one coupled atmosphere-ocean global climate model (GCM), two atmospheric GCMs, and two regional climate models (RCMs) covering all of Europe and a substantial fraction of the North Atlantic. In addition to these climate simulations, we also employ the ERA-40 reanalysis that provides an objective analysis of the observed atmospheric conditions for the time period 1958-2002. The use of different models is meant to provide an assessment of the intermodel spread and thus of the uncertainties of our conclusions. We consider simulations representing current and future greenhouse gas concentrations, using the IPCC SRES A2 scenario (IPCC 2001). Both periods comprise 30 years, 1961-90 (CTL) and 2071-2100 (A2) for current and future climatic conditions, respectively.

A considerable fraction of the climate model data employed has been derived within the European consortium project "Prediction of Regional scenarios and Uncertainties for Defining EuropeaN Climate change risks and Effects" (PRUDENCE, Christensen et al. 2002; Christensen and Christensen 2007, see also http://prudence.dmi.dk/). Therein, systematic ensembles of RCM simulations over the West-Atlantic / European region were conducted at a horizontal resolution of typically $0.5^{\circ} \times 0.5^{\circ}$. 
The PRUDENCE model chain starts with the Hadley Centre HadCM3, a global coupled atmosphere-ocean model. The HadCM3 simulation is a long low-resolution integration using the observed atmospheric composition for 1859-1990 and scenario conditions for 1991-2100 (Johns et al. 2003). Mean changes (A2-CTL) in seasurface temperature and sea ice from this simulation were used in the subsequent higher-resolution simulations. The next step in the model chain is represented by atmospheric GCMs. We use output of two GCMs, the Hadley Centre HadAM3 (Pope et al. 2000) and the Max-Planck-Institute ECHAM5 (Roeckner et al. 2003, 2006), both with a resolution of approximately $1^{\circ}$. These models are run in time-slice mode for the CTL and A2 periods. Prior to the 30 year simulations, 5 years of the simulation have been disregarded to account for potential spin-up effects. The output from the time-slices is used to drive two RCMs, the CHRM and the CLM, at a spatial resolution of $0.5^{\circ}$ and 20 vertical levels.

A total of eight regional climate models (RCMs) are provided by the PRUDENCE project, but we are using only two of these models. Both the $10 \mathrm{~m}$ horizontal wind and $10 \mathrm{~m}$ gusts are provided by the PRUDENCE project at daily resolution. The $10 \mathrm{~m}$ wind speed represents the daily average length of the wind vector, while the daily maximum length of that wind vector reached during the simulation time interval yields the $10 \mathrm{~m}$ gust field. Hence the gust field is much more representative of the maximum speeds reached during a storm event. In a more detailed comparison of the performance of these two input wind fields in our analysis, the gust wind speeds did indeed yield more realistic results. However, it has also been noted that due to the large inter-model differences in the calculation of the maximum $10 \mathrm{~m}$ wind, the entire distributions (pdfs) of the gust speeds differ between models by a factor of 10. Rockel and Woth (2007) discuss the problems with the inconsistent $10 \mathrm{~m}$ wind calculations within PRUDENCE. In particular, they analyze and verify the quality of the $10 \mathrm{~m}$ gust speeds in great detail. In line with our pdf-analysis they show that only the RCMs that operate a specific gust parameterization (models CLM and CHRM) produced much higher and more realistic gust speeds than the other models. CHRM and CLM use the same gust parameterization (Schrodin 1995) and determine the maximum wind based on the output of every time step of the simulation. Hence we restricted our analysis to these two models. On a more general note, we add that care is to be exercised in the analysis of gust fields, which typically are not very smooth, and can have large gradients, especially near coast lines, with an increased possibility of grid point wind storms.

The limited-area model CHRM derives from the operational weather forecasting model HRM of the German and Swiss meteorological services (Majewski 1991), which has been adapted into a climate version by ETH Zürich (Lüthi et al. 1996; Vidale et al. 2003). The model is hydrostatic and has a full package of physical parameterizations, including a mass-flux scheme for moist convection (Tiedtke 1989) and Kessler-type micro-physics (Kessler 1969; Lin et al. 1983). A detailed description of the actual model version and further evaluations are given in Vidale et al. (2003). Here we employ the same model simulations as validated and analyzed in the context of the PRUDENCE project (e.g. Christensen and Christensen 2007) and in recent scenario and process studies (Schär et al. 2004; Vidale et al. 2007).

The climate version of the Lokalmodell (CLM) has the same dynamic and physical core as the weather forecast model LM (Lokalmodell) of the German Weather Service (DWD). The CLM is nonhydrostatic and fully elastic. Moist convection is 
parameterized by the mass flux convection scheme after Tiedtke (1989) modified by using a CAPE-closure. Prognostic cloud ice parameterization and prognostic TKE scheme are switched on for simulations CTL and A2. For more details refer to Steppeler et al. (2003), and http://cosmo-model.cscs.ch/public/model.htm. Again, the CLM simulations used in the current study have previously been analyzed by Rockel and Woth (2007). Both the CLM and the CHRM are driven at the lateral boundaries following Davies (1976), using a boundary updating frequency of $6 \mathrm{~h}$. Sea-surface temperatures are taken from the driving simulation, while soil and snow conditions are interactively established using the models' land-surface modules.

As an alternative and complementary data source for our analysis, we also performed simulations that are not formally part of the PRUDENCE project, but which follow the PRUDENCE strategy in their design: two additional 30-year CHRM simulations (CTL and A2) were nested into the global climate model ECHAM5 (for a description see Roeckner et al. (2006) and companion articles in the same special issue). The ECHAM5 runs were undertaken at T106L31 using the standard dynamical properties, but PRUDENCE SSTs. For an overview of the realism of the resulting variability patterns cf. for instance Raible et al. (2009). Note that although the SST/sea-ice input for the global atmospheric models is the same, they nevertheless provide additional variability due to different model configurations and formulations. The use of independent global models aids the estimation of the uncertainty inherent in climate model projections (cf. Schwierz et al. (2006)). Thus the analysis presented here is undertaken with the smallest possible multimodel ensemble of three sets of model runs, where the inter-model uncertainties are mimicked to a certain degree by the use of the models CHRM and CLM, while uncertainties due to a variation in the initial and boundary information is partly accounted for by driving the regional models with the two different global atmospheric model outputs.

In an additional simulation the 44-year (1958-2002) re-analysis data set of the European Centre for Medium-Range Weather Forecasts (ECMWF ERA40, Uppala et al. 2005) was used as an independent and observationally constrained data source to drive the regional model CHRM, in the same way as for the HadAM3 and ECHAM5 boundary data, but for a longer time period (up to 2001). The dynamical evolution within the CHRM domain closely follows the real development. It can hence be used to develop and test the storm-day selection routine. The resulting criterion is then directly applicable to the climate CTL and A2 simulations, since it is derived with the same model chain rather than from a different (e.g. observational) data source.

In effect, the regional model runs provide a dynamically down-scaled data set that contains much more detail and accuracy than the global models, which is crucial in particular for terrain-dependent parameters such as low-level winds and gusts. Although computationally much more expensive, dynamical downscaling is superior to statistical methods in the sense that the dynamical equations are fully solved and thus the model atmosphere can develop high-resolution features that are dynamically consistent. Also it does not rely on the preparation of an observational predictor data set.

Thus the complete meteorological data set analyzed here comprises gust output from 7 RCM runs, i.e. HC-CHRM, HC-CLM, ECHAM5-CHRM (each with a 
CTL and A2), and ERA40-CHRM. Here HC stands for HadCM3/HadAM3 lateral boundary conditions, while ECHAM5 stands for HadCM3/ECHAM5 boundaries.

\subsection{Insurance data and models}

The proprietary loss model by the Swiss Reinsurance Company is based on four modules (see Fig. 3): (i) The hazard module is concerned with the location, frequency, intensity and length of the occurred events. The hazard is described with a frequency distribution of different event intensities and duration factors at the model's geographical resolution. A sample wind gust map (of the maximum intensity in the probabilistic set) is given in Fig. 3a. (ii) The vulnerability module accounts for the extent of the damage (mean damage ratio in percent of total sum insured) at a given event intensity. A vulnerability curve is derived from past damage history (cf. Fig. 3b) for each risk type (e.g. residential, commercial, industrial and agricultural). (iii) The value distribution describes the amount (total sum insured), location and risk type of the insured values. It is usually available in national administrative districts or sometimes at higher resolution and disaggregated according to population density. (iv) The insurance conditions comprise all the information on the contract conditions that determine the proportion of the loss that is insured. They can for instance encompass deductibles (self-retentions) and damage limits. No such insurance conditions have been applied in the present study for reasons of clarity.

In this study a slightly simplified version of the operational Swiss Re model is employed. It uses an average vulnerability curve for all risk types, and applies only one mean damage ratio value per wind speed, instead of a distribution. The operational model and its slightly simplified version lead to results (climate change
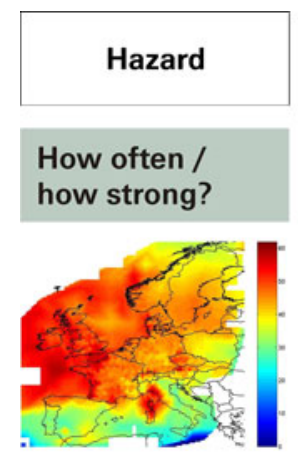
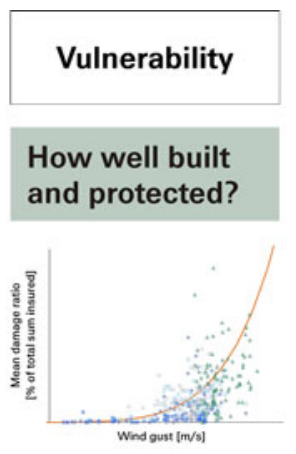

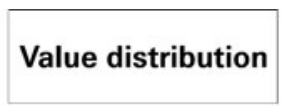

\section{Cover conditions}

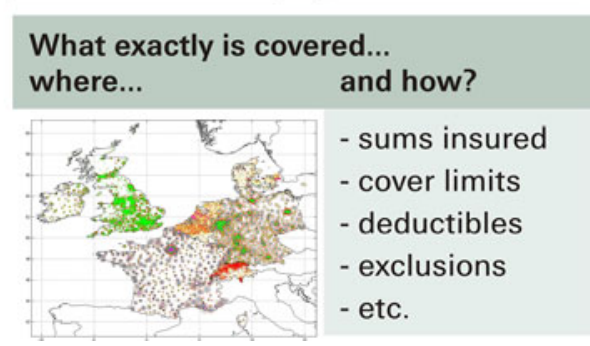

Fig. 3 Swiss Re loss model consisting of 4 modules (see text for details). The sample plots are a a wind gust distribution of the maximum intensity of the probabilistic set, $\mathbf{b}$ a sample vulnerability curve (red line) relating wind gust speed [m/s, ranging between $\sim 20-70 \mathrm{~m} / \mathrm{s}]$ to mean damage ratio [\% of total insured value, typically of the order of $0.01 \%$ ] based on recorded damage history (different symbols and colours are representive of different clients in the residentail sector), c a sample value distribution for several countries in central Europe and the risk types residential (red), commercial (green), industrial (blue) and agricultural (magenta). The resolution varies according to regional administrative borders, and the size of the circle represents the relative value of the asset per regional administrative entity (which varies in size from one entity to the other) 
impact) in the same order of magnitude. Details of the operational loss model and the simplifications made for this study are presented next.

In order to simulate a representative and more comprehensive selection of all possible events and to reinforce the statistics of the historical events in the hazard module, probabilistic modeling is used. On the basis of the known historical events and physical parameterizations, thousands of additional hypothetical events are generated by varying the intensity and the track of the storm in a Monte-Carlolike approach. Whilst these artificially generated events never actually took place historically, there is - from a statistical/scientific point of view-no reason why they should not occur at some point. The hazard module event set typically comprises tens or hundreds of thousands of events, which represent a model time frame of several thousands or several tens of thousands of years. In effect this is the way in which the return periods of particular loss amounts are determined. Such probabilistic sampling models can even take into account the effect of varying climatological conditions such as El Niño or the North Atlantic Oscillation by selecting the corresponding years before applying the Monte-Carlo module.

In this study, the technical details of the hazard module are as follows.

1) The historical event set is the operational one of SwissRe and comprises the major (143) events (including storms like Anatol, Lothar and Martin) from 1947 to present. These are available as so-called reconstructed "footprints" that are generated using dynamical parameters and relationships, such as the large-scale wind field, the frontal development, the post-frontal low-level jet to adjust for peak gusts, and including observational station data.

2) For the Monte-Carlo method, the historical footprints are spawned, taking the physical properties into account, through a dual process of (a) rigid motion and rotation and of (b) wind field intensity alteration. To this end the storms have been intensified/weakened and were shifted in all major directions (+/ -50 to $100 \mathrm{~km})$ and rotated (+/ -5 degrees) along their axis of movement etc. While scenarios derived via rigid motion and rotation are considered equally likely, this is not true for those derived via the wind field alteration. In order to have a large enough number of severe storms while not wasting computation time on thousands of almost identical small events, the probability weight of the intensity alteration is different for each historic scenario. In this way, 10010 events are generated, representing more than 3000 years of data.

3) In order to establish a sound intensity-frequency relationship, a calibration using the SSI (Storm severity index) according to Lamb and Frydendahl (1991) is applied. The synthetic storms were assigned probability weights such that the resulting SSI exceedance curve of the probabilistic event set matches the one of the historical event set.

4) To validate the procedure with an independent data set, peak gust return periods from selected meteo stations all across Europe are compared with peak gust return periods resulting from the probabilistic event set.

As a result the probabilistic event set matches well with history and extends it naturally, achieving a very good correspondence of the modeled (probabilistic) compared to observed (meteo stations) gust speeds for a range of return periods.

The vulnerability module (see Fig. 3b) takes into account various factors describing the insured risk. As it is not possible to analyze the characteristics of each and 
every insured object, classes with common vulnerability curves are defined, which are derived empirically. Figure $3 \mathrm{~b}$ illustrates point data for damage information for a variety of customers with respect to measured wind speed. From this, a mean damage ratio is derived. In order to allow for fluctuations within these categories, a random distribution around the mean damage ratio is used. In the simplified version of the loss model used in this study, only the mean value is used.

The European-wide property insurance portfolio used in this study is based on client data owned by the Swiss Reinsurance company which has a market penetration of about $80 \%$ and thus reflects the actual situation well. This has then been grossed up to obtain a distribution representative of the whole insured sum of the whole European market. Values are clustered in residential, commercial, industrial, and agricultural groups (see Fig. 3c). In the simplified version of the loss model used in this study, only one (residential) average vulnerability curve (cf. Fig. 3b) is used for all risk types (residential, commercial, industrial and agricultural). The vulnerability curve is based upon 1987 and 1990 events in the UK and cross-validated with other European countries. Note that the SwissRe model implements a holistic approach across all Europe, so storms do not stop at country boundaries, but that the vulnerabilities are country-, risk-type-, building-specific etc. Hence there are different vulnerability curves for e.g. residential and commercial risks in the UK, say, split into building and content, and e.g. small versus large residential buildings (or blocks). In the simplified version of the loss model used in this study, the analysis is performed on residential assets only.

When analyzing a portfolio of risks the entire probabilistic event set generated by the hazard module is applied to the whole portfolio. Using the remaining modules, an event loss is estimated for each of these events. The list of event losses allows the re/insurer to calculate the expected annual loss arising from the modeled hazard for the portfolio in question. This forms a basis for estimating average and extreme loss burdens and can be displayed in the form of a loss frequency curve (LFC). More details on risk assessment of natural hazards and reinsurance modelling can be gleaned from Zimmerli et al. (2003).

\section{Methodology}

\subsection{Strategy}

The coupled climate-insurance model chain basically works in three steps and is undertaken consistently for the CTL and A2 simulations. First a selection criterion is applied to the meteorological wind gust fields from the regional climate model runs to extract the potential storm days. Then the selected meteorological data is used as the input for the generation of a probabilistic event set by the hazard module and the subsequent calculation of the damage to the European-wide market portfolio by Swiss Re's loss model. The consistent evaluation of the CTL and A2 scenario runs finally yields the predicted climate change impact on winter wind-storm insurance losses. For step 1 a selection criterion is developed based on the ERA40-CHRM simulation. Step 2 involves a calibration of the current-day RCM-based probabilistic event set against the annual expected loss (AEL) of Swiss Re's historical losses. 
The entire approach can be viewed in the context of probabilistic frameworks as opposed to a method that is suitable for individual wind events. This characteristic stems from the nature of the insurance model, which has not been designed to determine the damage produced by a single storm at a particular site, but aims at estimating the loss on a whole portfolio and hence retrieving statistical return periods for windstorm events. Ultimately, the desired quantity is the climate impact on the cost of these return periods. Hence the underlying objective was to achieve a simple, but dynamically meaningful procedure and the requirements for the meteorological selection criterion are: -to detect the significant wind events, -be easy to apply, e.g. a grid-point-based criterion, -dismiss spurious grid-point storms that are often found in models at exposed sites such as coastline-grid-points.

\subsection{Selection criteria}

The development of the selection criteria has been undertaken with the ERA40CHRM run to allow for validation against historical storm days. For this study only land-points have been taken into account, defined from the models' land-sea mask (land ratio $>80 \%$ ). The criterion is applied locally (grid-point). Instead of an absolute threshold, the wind speed relative to the $98 \%$ quantile (V98) of the local gust speed distribution is considered, where the underlying statistics is defined by the full ERA-40 driven simulation. Days with extreme gusts, in excess of this ratio by $30 \%$ (i.e. v/V98 > 1.3), are selected. A similar approach was used by Klawa and Ulbrich (2003) for their loss parametrization. In addition, to address the gridpoint storm problem, our criterion had to be met by at least 3 grid points. A nearest neighbor criterion was also tested, but finally not applied, because it involves making assumptions about the shape of the storms' gustfield footprint, which-to be more than completely arbitrary-would require a level of detail beyond the scope of this study. Finally the data set was reduced further by requiring a minimum wind speed larger than $15 \mathrm{~m} / \mathrm{s}$. This corresponds to the insurance model's cut-off below which the loss is negligible.

The final thresholds parameters have been found through a number of sensitivity studies by applying the set of criteria to the ERA40-CHRM data and validating the results with historical storm data. The set of thresholds and criteria mentioned above extracts all the major storms of the last 40 years satisfactorily, among them significant events such as the Hamburg-storm (1962), Capella (1976), Daria (1990), Vivian (1990), Wiebke (1990), Lore (1994), Anatol (1999). Even fast-moving and small-scale events such as the winter storms Lothar (1999) (cf. Wernli et al. 2002) and Martin (1999) are captured. As an example Figure 4 shows the CHRM gust field of the severe winter storm Daria, together with the identified grid-points from the selection routine. The maximum gust speed is affecting a wide area ranging from southern England, over the Channel, into northern Germany. This is indeed the region which was most severly damaged in the storm event (Swiss Re, personal communication). The grid points selected in our approach (black stars in Fig. 4) cover the land points within the maximum gust region.

Figure 5 gives an overview of the (CHRM) model performance and the effect of the selection criteria in terms of three gust distributions from the ERA40-CHRM run. From Fig. 5a the general structure of the time-averaged winter gust field (AVG) can be discerned. Average gusts are generally much reduced over land $(\sim 9-11 \mathrm{~m} / \mathrm{s})$, 
Fig. 4 Example to illustrate the selection criterion (see text for details). ERA40-CHRM gust speed $[\mathrm{m} / \mathrm{s}]$ (shaded) and selected land grid points overlaid (black stars) for the historic winter storm "Daria", that occured from 25.-26.1.1990 over Northern Europe. Cf. Fig. 2

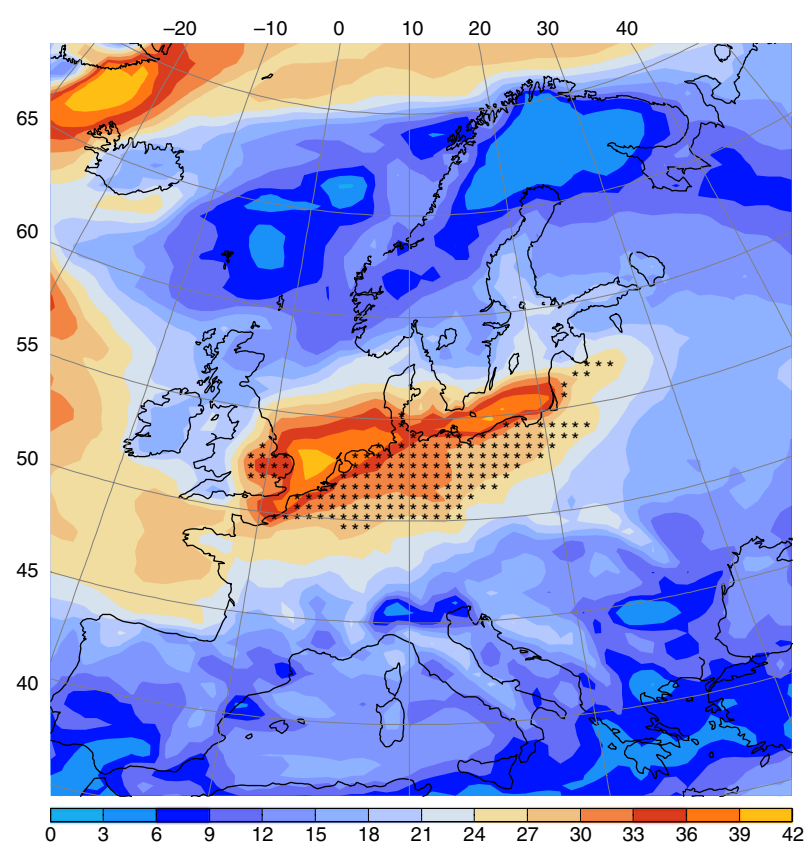

with local minima at the major orographic obstacles $(\sim 6-8 \mathrm{~m} / \mathrm{s})$. Maximal gusts occur within the North-Atlantic storm track $(\sim 20 \mathrm{~m} / \mathrm{s})$ and in a narrow band along the coast line $(\sim 13 \mathrm{~m} / \mathrm{s})$. Additional local maxima are present in the German bight and the Baltic Sea $(\sim 15-16 \mathrm{~m} / \mathrm{s})$. The structure of the simulated orographicallyinduced Mediterranean wind maxima such as the Mistral at the south coast of France $(\sim 15 \mathrm{~m} / \mathrm{s})$, the Strait of Gibraltar $(\sim 13 \mathrm{~m} / \mathrm{s})$, the Etesian south of Greece $(\sim 13-14 \mathrm{~m} / \mathrm{s})$ and an indication of the Bora in the Adriatic Sea $(\sim 13 \mathrm{~m} / \mathrm{s})$ compares well with observations (e.g. the 5-year scatterometer climatology by Zecchetto and

(a) mean gust (AVG)

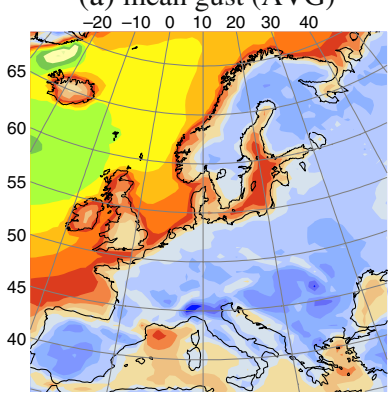

(b) $98 \%$ quantile (V98)

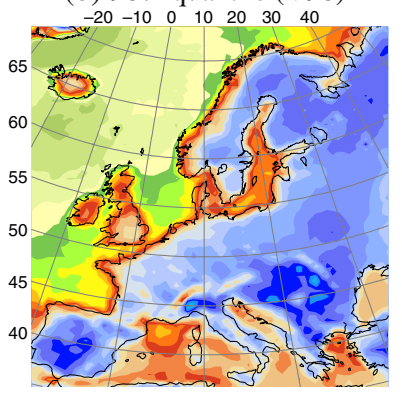

(c) mean gust events (MGE)

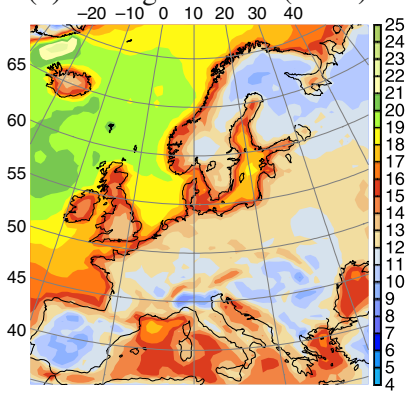

Fig. 5 ERA40-CHRM 10m gust fields [m/s] for the winter months Oct-Mar (shaded) for the period (1961-1990). a Mean gust speed, b local 98\% quantile, and $\mathbf{c}$ mean gust of all days extracted with the selection criteria. Contour interval $1 \mathrm{~m} / \mathrm{s}$. Note that in $\mathbf{b}$ the contour values are $10 \mathrm{~m} / \mathrm{s}$ larger 
Cappa (2001)). The 98\% grid-point quantile, V98, (Fig. 5b) shows a similar spatial distribution, albeit with roughly doubled gust strengths and a clearer distinction of the local wind maxima. In addition, the Alpine ridge exhibits a local maximum $(\sim 25 \mathrm{~m} / \mathrm{s})$. After application of the wind selection criterion the gust fields for each 'wind event' have been averaged in Fig. 5c (MGE). Recall that the wind threshold criterion only has to be exceeded locally, but that the gust intensity can nevertheless be average farther afield, which impact the maximum MGE values obtained through averaging over all events. In comparison to the average gusts (Fig. 5a), a general increase of the mean gust speed of $\sim 2-3 \mathrm{~m} / \mathrm{s}$ is apparent for the selected days. The land gusts hence range from $8-14 \mathrm{~m} / \mathrm{s}$, German bight and Baltic Sea $\sim 18 \mathrm{~m} / \mathrm{s}$, Mediterranean maxima $\sim 15-17 \mathrm{~m} / \mathrm{s}$, coast lines $\sim 15 \mathrm{~m} / \mathrm{s}$. The structure remains very similar to the average gust field.

In summary, the effect of the selection criterion is a significant and dynamically meaningful reduction of the original data set from 5400 days (Oct-Mar 1961-90) to 351 input fields $(\approx 86.5 \%)$ in the case of the ERA40-CHRM data set. After the selection of the wind-event days, the total spatial gust fields are retrieved for all events and remapped to Swiss Re's model grid for all model runs considered.

\subsection{Calibration}

The RCM-gust fields, although downscaled to a relatively high resolution, are still a smoothed and low-amplitude version of real gust values. Therefore, in order for the coupled model chain to be able to deliver acceptable losses, a calibration of the gust fields is necessary before the vulnerability module can be set in operation. Additionally, due to the high non-linearity of the vulnerability function, one has to ensure that the windfields of the CTL run lie within the same sensitivity band of the vulnerability function as in the operational tool. A useful reference for the calibration are Swiss Re's relatively long-standing experience loss values (the company has been in business since 1863 and data records cover several decades). In addition, these experience values have been continuously used in conjunction with additional data, such as observed gust station records and spatial wind information from synoptic analyses, to build and improve Swiss Re's operational model. Hence good estimates are available from the past for the annual expected loss (AEL), and in particular for the high-frequency part of the LFC. Thus the model gust calibration is performed against the operational AEL value.

To this end, probabilistic sets are generated for each of the three CTL data sets and the ERA40- CHRM by the hazard module. From these the AEL can be calculated. Iteratively, the intensity measure $(\mathrm{m} / \mathrm{s})$ of the CTL runs is calibrated such that the "probabilistic" CTL runs amount to the same annual expected loss (AEL) as the operational model. The procedure converges after 10 iterations with an adjustment accuracy in the range between $-6.1 \%$ (HC-CLM) to 1.9\% (HC-CHRM), and the so-derived multiplicative calibration factors amount to values between $9 \%$ and $22 \%$ (see Table 1 for all details). The sensitivity with respect to the chosen calibration domain is small. The calibration has been performed both Europeanwide and for the individual countries, but the calibration results are similar and hence only the European scale is considered for the calibration. Performing the calibration for Germany, for instance, leads to differences in climate change impacts of $0-5 \%$, depending on the model. 
Table 1 Calibration precision of the annual expected loss and resulting gust adjustment factors

\begin{tabular}{llll}
\hline & ECHAM5-CHRM & HC-CHRM & HC-CLM \\
\hline $\begin{array}{l}\text { Truncated annual expected loss } \\
\text { calibration precision }\end{array}$ & $1.9 \%$ & $-6.1 \%$ & $0.2 \%$ \\
Gust adjustment factor & 1.22 & 1.17 & 1.09 \\
\hline
\end{tabular}

The AEL calibration method is chosen against several alternative pdf-calibration approaches, which have also been tested. These entailed using gust wind fields (not enough observational data), or the storm severity index (Lamb and Frydendahl 1991) (no straightforward relation to loss or input gust field).

Now the selection criteria and calibration are applied to both CTL and A2 runs for the three RCMs and the expected loss changes in a warmer climate are determined.

\section{Results}

\subsection{Control simulations}

As prerequsite for the climate change impact study, an intercomparison of the base fields (mean wind gusts AVG, V98, mean gust of event days MGE) from the three different regional model runs nested into the two global climate models for present day conditions (CTL) is undertaken with Fig. 6. These results (in particular Figs. 6a, b) can also be related back to Fig. 5, where CHRM has been driven by the ERA40 reanalysis, which will be treated as representing "reality" for the current intercomparison. The plots show interesting similarities and differences and together provide an insight into the uncertainty range inherent to the various steps of the climate model chain.

The overall structure and patterns of both AVG and V98 (Fig. 6; top and middle) are very similar for all simulations. In particular both CHRM climate simulations (Fig. 6a, b; top) bear close comparison with the downscaled ERA40 data (Fig. 5a). Hence it can be argued that the CTL runs are able to reflect satisfactorily the current climate gust conditions. A good correspondence between observed and simulated cyclone tracks and wind fields has similarly been reported in other studies using the HadCM3/HadAM3 modeling chain (Leckebusch and Ulbrich 2004; Rockel and Woth 2007; Pinto et al. 2007).

However, noteworthy differences exist. Firstly, it is interesting to record that the gust fields differ significantly less between the two regional models (using the same global model, Figs. 6b, c), than a single regional model (CHRM) driven by different global models (Figs. 6a, b). This confirms the importance of including the uncertainty related to different global climate models (GCMs) into nested regional impact studies.

Secondly, a closer look at the regional models driven by the same GCM (Figs. 6b, c) reveals only minor deviations over the oceans, but considerable differences over land, i.e. Spain, Great Britain, European continent. There, AVG and V98 values in HC-CHRM are reduced by about $1-2 \mathrm{~m} / \mathrm{s}$ and $2-4 \mathrm{~m} / \mathrm{s}$, respectively, compared to HC-CLM. An exception is Scandinavia where values and structure remain more similar. 
(a)

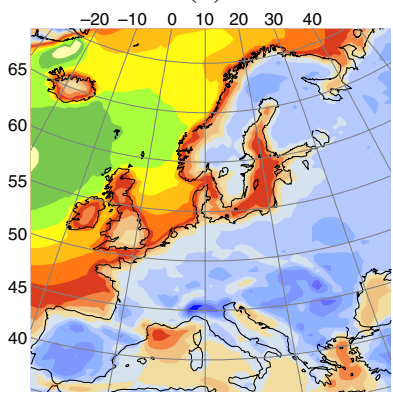

$\begin{array}{lllllll}-20 & -10 & 0 & 10 & 20 & 30 & 40\end{array}$
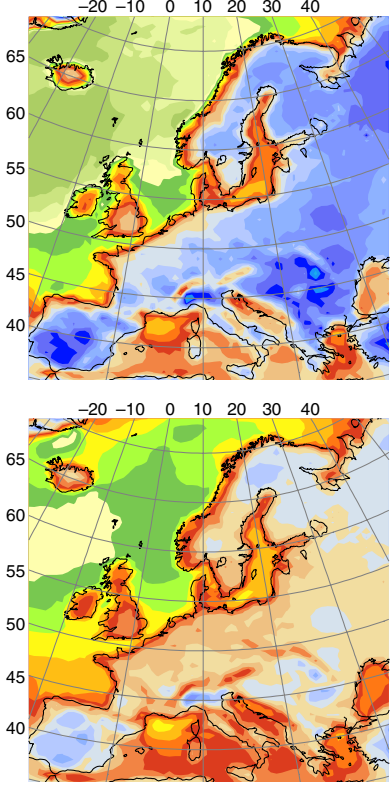

(b)

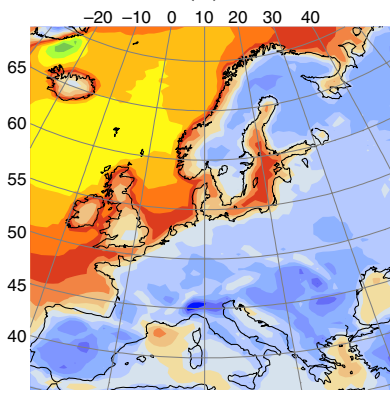

$\begin{array}{lllllll}-20 & -10 & 0 & 10 & 20 & 30 & 40\end{array}$
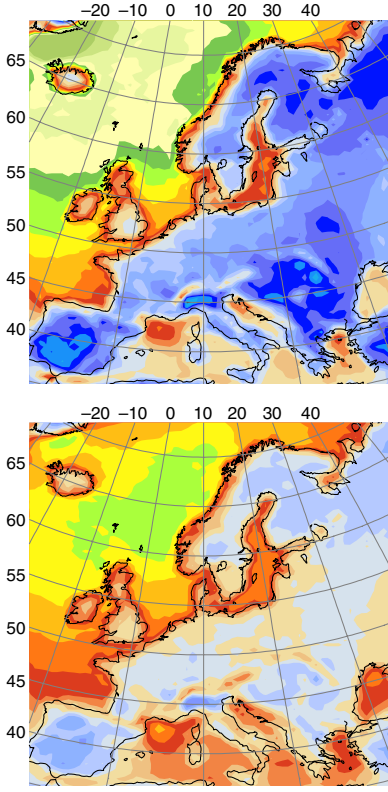

(c)
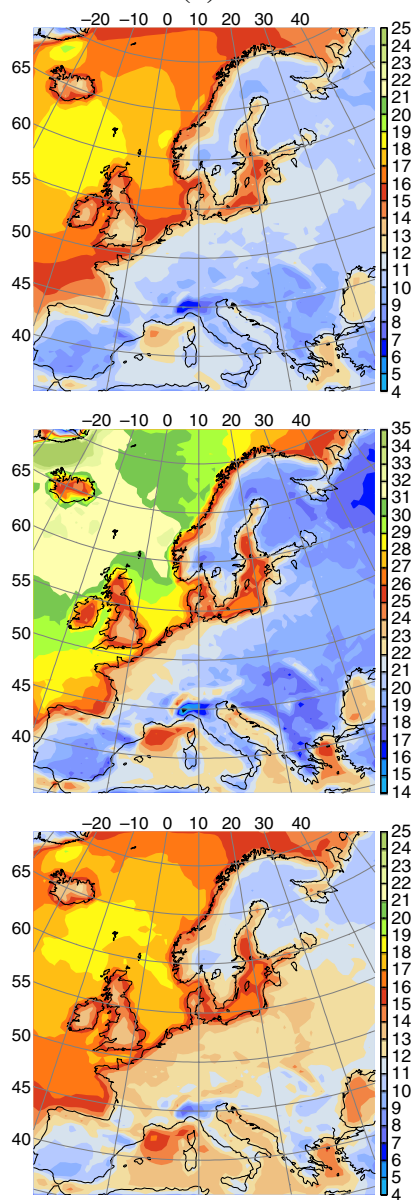

Fig. 6 Comparison of mean gust fields (top, AVG), local 98\% quantiles (middle, V98) and mean gust for all selected event days (bottom, MGE) for the three nested RCM CTL runs for Oct-Mar 1961-1990 (shaded, m/s, contour interval 1 m/s). a ECHAM5-CHRM, b HC-CHRM, c HC-CLM. Note that the contour values are $10 \mathrm{~m} / \mathrm{s}$ larger for V98

Thirdly, further intercomparison of V98 over land shows that the CLM exceeds all other model runs by $1-4 \mathrm{~m} / \mathrm{s}$. In terms of V98 it is followed by the ECHAM5-CHRM, ERA40-CHRM and then HC-CHRM. HC-CLM and to a lesser degree ECHAM5CHRM also exhibit positive offsets over the land areas for AVG. Possible reasons are differences in the friction/roughness parametrizations, differences in storm tracks with the local wind maximum protruding farther into the Gulf of Biscay (CLM), and the generally stronger wind speeds particularly over the oceans (ECHAM5).

Fourthly, the local V98 maxima over the oceans (Baltic Sea, German bight, Mediterranean) are less intense $(2 \mathrm{~m} / \mathrm{s})$ in the HC-driven run (Fig. 6b) than in both the ECHAM5-CHRM (Fig. 6a) and ERA40- CHRM (Fig. 5).

From the above the following conclusions about the structure of the gust probability distribution functions (pdf) can be drawn. Over water, the means of the 
ECHAM5-CHRM and ERA40-CHRM wind pdfs are comparable, but underestimated by HC-CLM and HC-CHRM. Over land the mean is overestimated by HCCLM and underestimated by HC-CHRM. These differences are more pronounced for the extremes of the pdf, where heavy tails are featured by ECHAM5-CHRM over the ocean, and by HC-CLM over land. HC-CHRM gust extremes fall off strongest, in particular over land areas.

Finally, the event gusts (MGE) are the relevant fields for the coupling to the insurance model (Fig. 6, bottom row and Fig. 5c). The losses and selection criteria are only calculated over land, and the resulting sample sizes underlying Fig. 6 amount to 335 (ECHAM5-CHRM), 308 (HC-CHRM) and 665 days (HCCLM). Note that the overall structure of the MVG field is similar to the AVG. More specifically, over land, ECHAM5-CHRM and HC-CLM show the highest MVG values and HC-CHRM the lowest (with the exception of Scandinavia and Great Britain). For completeness we mention that over the ocean HC-CLM has weaker winds by $1-2 \mathrm{~m} / \mathrm{s}$ in comparison to HC-CHRM, which itself is $2-4 m / s$ less than ECHAM5- CHRM (storm track, Baltic Sea).

The previous observations stress the advantage of applying the multi-model approach on all levels of the model hierarchy. They also point to the possibility of obtaining a sizeable range in damage results, since the largest spread between the regional models is observed over land.

\subsection{Climate simulations (A2)}

Before proceeding with the estimation of wind damages, we consider the changes in the gust fields in a warmer climate (A2-CTL). Figure 7 reveals the changes to gust fields expected in the A2 scenario, for the 3 nested RCM simulations. Given the existing differences in the CTL gust fields (Section 4.1) it is reassuring that the overall changes recorded in all model runs exhibit a consistent structure and amplitude range.

The climate change pattern that stands out most is the increase in gust speeds in a broad band stretching from the Atlantic, over Great Britain into Northern and Central Europe. The increase is felt strongest in the ECHAM5-CHRM, where it extends farthest to the east with a signal all the way to Eastern Europe. This area of gust increase is straddled by two adjacent bands of reduced gusts spanning from the Northern Atlantic to Scandinavia, and from Spain to the Eastern Mediterranean Sea.

The maximum of the AVG increase is in the English channel and the German bight $(0.8-1.4 \mathrm{~m} / \mathrm{s}$, corresponding to a $6-8 \%$ increase), and it is weaker $(0.4-$ $0.8 \mathrm{~m} / \mathrm{s}, 3-7 \%$ ) over the NW-European continent. The decrease over Iceland and Scandinavia is of a similar magnitude $(-1.2 \mathrm{~m} / \mathrm{s}, \sim 6 \%)$, while the impact over the Mediterranean amounts to only half of that $(-0.4 \mathrm{~m} / \mathrm{s}, \sim 3 \%)$. The same change in structure is predicted for V98, pointing to the fact that the entire gust-pdf will shift to higher values in a corridor across Western and Central Europe. The relative change at the tail of the distribution, however, is less than that of the mean, suggesting changes in variance and/or skewness of the pdf. V98 values increase by $0.8 \mathrm{~m} / \mathrm{s}$ $(\sim 3 \%)$ near the channel, and decrease by $1.2 \mathrm{~m} / \mathrm{s}(\sim 4 \%)$ and $0.8 \mathrm{~m} / \mathrm{s}(\sim 3 \%)$ over Iceland/Scandinavia and the W-Mediterranean Sea, respectively. 
(a)

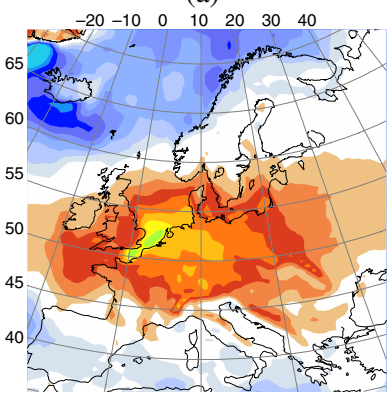

$\begin{array}{lllllll}-20 & -10 & 0 & 10 & 20 & 30 & 40\end{array}$
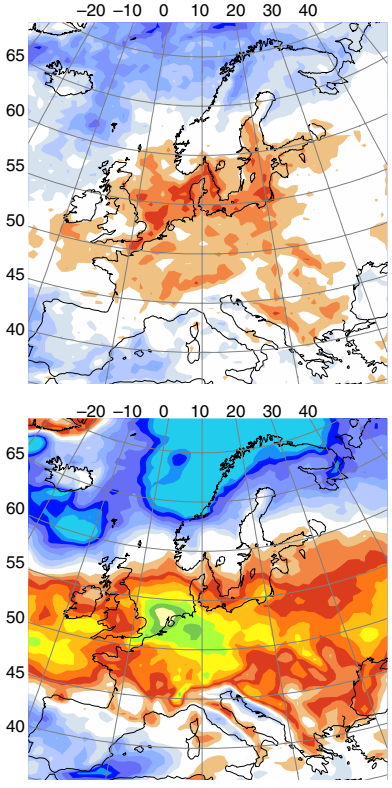

(b)

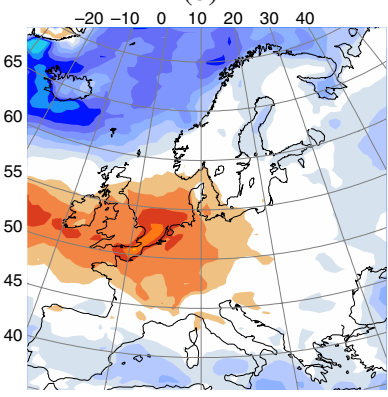

$\begin{array}{lllllll}-20 & -10 & 0 & 10 & 20 & 30 & 40\end{array}$
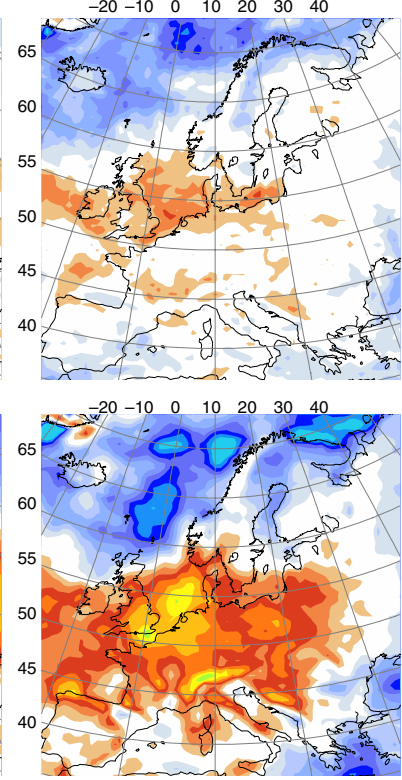

(c)
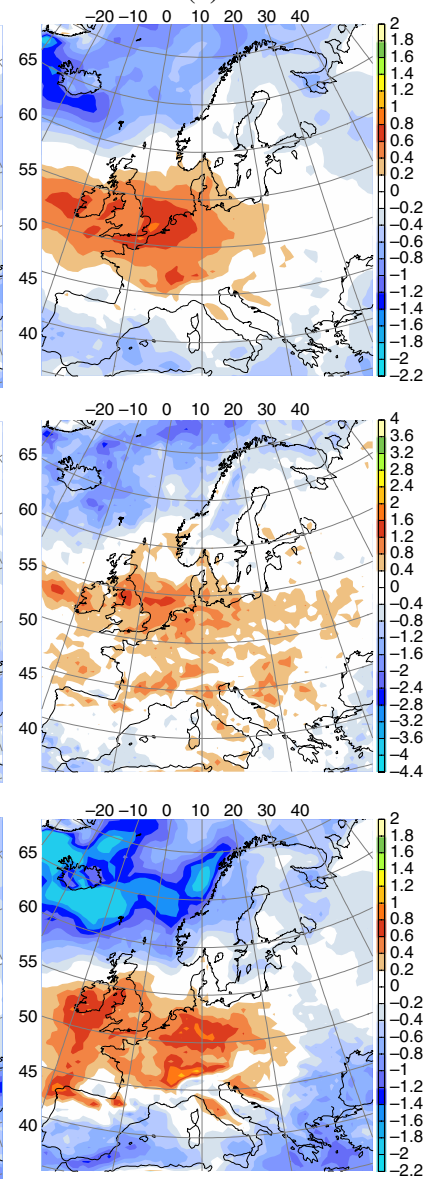

Fig. 7 Climate change impact on winter gust fields. As for Fig. 6, but shown is the difference between the A2 scenario (Oct-Mar 2071-2100) and CTL (Oct-Mar 1961-1990). Note the different contour values for each set (row) of figures. a ECHAM5-CHRM. b HC-CHRM. c HC-CLM

Applying the same selection criteria as for the CTL runs (v/V98_CTL $>1.3$ ) to the A2 simulations yields an increase in the overall number of selected events in a warmer climate. ${ }^{1}$ Hence in addition to the increase in the strength of the gusts recorded above, the frequency of the selected events appears to rise. However, there are large regional differences and these will be discussed in the next section. The spatial structure for MGE is again similar to the AVG and V98, and hence confirms that the selection criteria result in a useful reduction of the initial data set. Quantitatively, the MGE changes are larger than for AVG and V98: a 6-8\% $(1-1.5 \mathrm{~m} / \mathrm{s})$ increase over the English channel/German bight, and decreases of $8-10 \%$ $(1.5-2 \mathrm{~m} / \mathrm{s})$ over Iceland/Scandinavia and $\sim 7 \%(1 \mathrm{~m} / \mathrm{s})$ in the W-Mediterranean.

${ }^{1}$ ECHAM5-CHRM (364), HC-CHRM (302), HC-CLM (871). 


\subsection{Changes in return periods}

As outlined above (Sections 2.2 and 3.1) we now step from one modeled event set per climate run to the stochastic generation of a much larger, physically consistent, probabilistic event set that enables us to calculate wind fields for return periods much longer than the original 30-year integration period (cf. Section 2.2).

Figure 8 shows the climate-change induced differences in gust amplitudes that can be expected for events with a return period of 10, 30 and 100 years, respectively. The three models show a high degree of consistency in both the spatial pattern and the amplitude range between the different time horizons. The patterns also relate closely to the gust field changes (AVG, V98) from Fig. 7. However, the two figures show distinct information (mean wind field for all events vs. local wind speed for a particular return period) and should not be compared in detail. Note also that the fields in Figs. 7 and 8 are purely statistical information and bear no physical

\section{a) ECHAM5-CHRM}
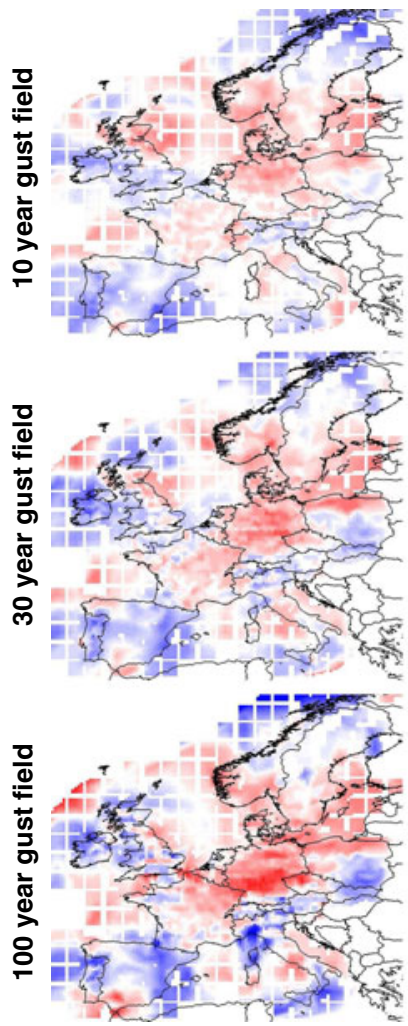

\section{b) HC-CHRM}
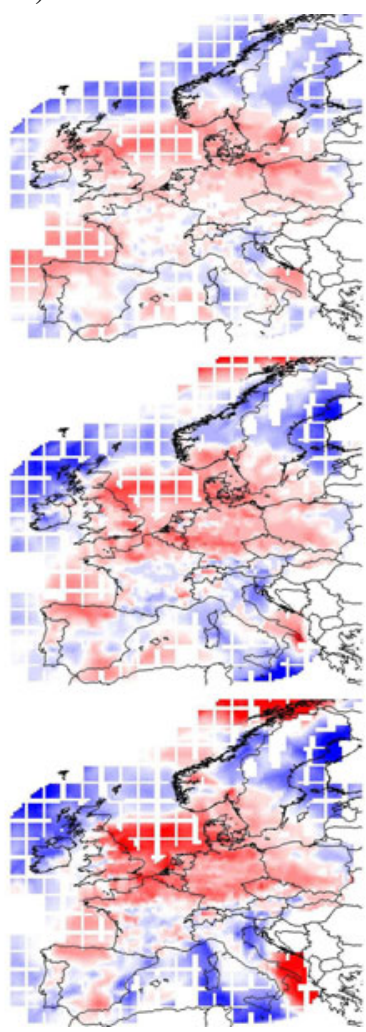

c) HC-CLM
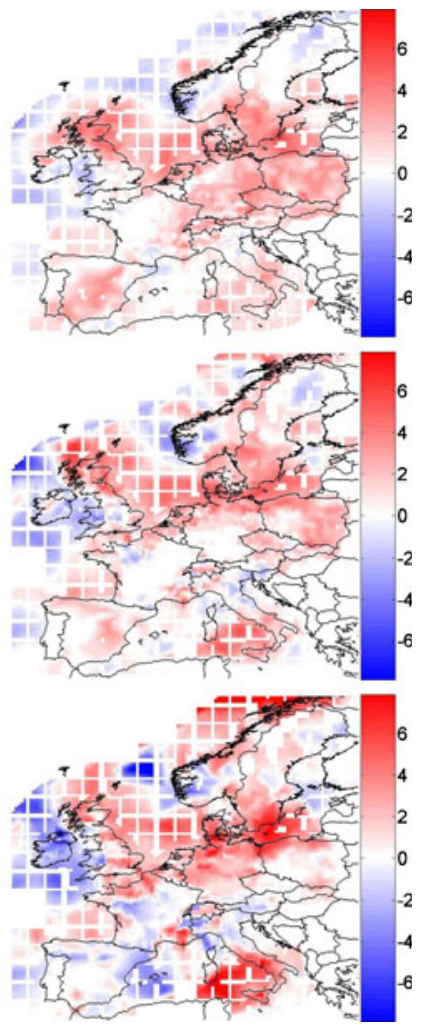

Fig. 8 Climate change impact on storm gust fields for different return periods, (top) 10 years, (middle) 30 years, (bottom) 100 years. Shown is the difference in event amplitude between the A2 scenario (Oct-Mar 2071-2100) and CTL (Oct-Mar 1961-1990) for the given return periods (shaded, $\mathrm{m} / \mathrm{s}$, contour value range is between $+/-8 \mathrm{~m} / \mathrm{s}$ ), based on the probabilitstic event sets. See text for details. The data is represented on the irregular insurance model grid. a ECHAM5-CHRM. b HC-CHRM. c HC-CLM 
meaning: i.e. the wind fields shown will in general not match any physically realised wind field in the data set. There are no obvious quantitative differences between the different model results (Fig. 8a-c). Expected changes tend to be larger for the rarer events (bottom panels) and amount to changes by up to about $+/-8 \mathrm{~m} / \mathrm{s}$. The consistent changes for the return periods comprise: -a decrease in event amplitude over Northern and Central Scandinavia, -a decrease over Ireland, -an increase over Southern Scandinavia, Northern Great Britain, the English channel and the North Sea, the Low countries, Germany (most dramatic over Northern Germany), and extending towards Poland and the Baltic States, -an increase over Southern Italy and the Adriatic Sea.

There is also some potential for an increase in extreme gusts over the Alps. Less certain and weak are the changes that occur over France, where an increase is projected for lower return periods, but the results are inconclusive for the higher return periods. Models are inconsistent over Southern Great Britain, where HCCHRM shows an increase while the other two models predict a decrease. Similarly although rather strong signals are present over Spain, the results are contradictory and no conclusion can be drawn. An explanation for the latter shortcomings can be sought through the observations made earlier (Figs. 6,7), which exhibit complex and non-conform model behavior over Spain.

\subsection{Changes in losses-climate change impact}

The generated probabilistic event sets are the input for Swiss Re's insurance loss model, which is applied to the market portfolio (cf. Section 2.2). The resulting climate change impact for insured winter storm losses is calculated with each of the three model chains and then evaluated in two complementary ways. First, the losses that occur in a particular frequency range (AEL, 10-year, 30-year, 100-year) for the entire European portfolio are given in Table 2 and plotted in Fig. 9. This information is subsequently regionalized by countries and shown for the AEL-level in Fig. 10. The error bars in these figures encompass the results of the three model chains considered.

From our analysis it can be seen that the area-mean impact is positive for all frequency bands and models considered (Fig. 9, Table 2). For the annual expected losses AEL, the results exhibit a mean increase of $44 \%$, with an uncertainty range provided by the model ensemble between $16 \%-68 \%$. For longer return periods the expected European-wide change increases non-linearly from $23 \%$ (10-years) to $50 \%$ (30-years) and to $104 \%$ for the 100 -year loss. The change is least significant for the 10 -year events. The associated model spread is particularly large for the rare events $(53 \%-156 \%)$. In summary, the more infrequent an event, the greater the increase in expected loss. In economic terms, the loss increase is disproportionately large for the high layers. To illustrate the implications, consider the following numerical example

Table 2 Climate change impact on the European market portfolio for the annual expected loss (AEL), the 10-, 30- and 100-year loss

\begin{tabular}{lccc}
\hline Climate impact & ECHAM5-CHRM & HC-CHRM & HC-CLM \\
\hline 1-year loss (AEL) & $16 \%$ & $68 \%$ & $48 \%$ \\
10-year loss & $3 \%$ & $39 \%$ & $25 \%$ \\
30-year loss & $13 \%$ & $93 \%$ & $45 \%$ \\
100-year loss & $53 \%$ & $156 \%$ & $105 \%$ \\
\hline
\end{tabular}


Fig. 9 Mean climate change impact on the European market portfolio for the annual expected loss (AEL), and the losses with return periods of $10-, 30-$ and 100-years. Uncertainty bars show the range of the three different coupled model outputs. See Table 2 for individual precentage values

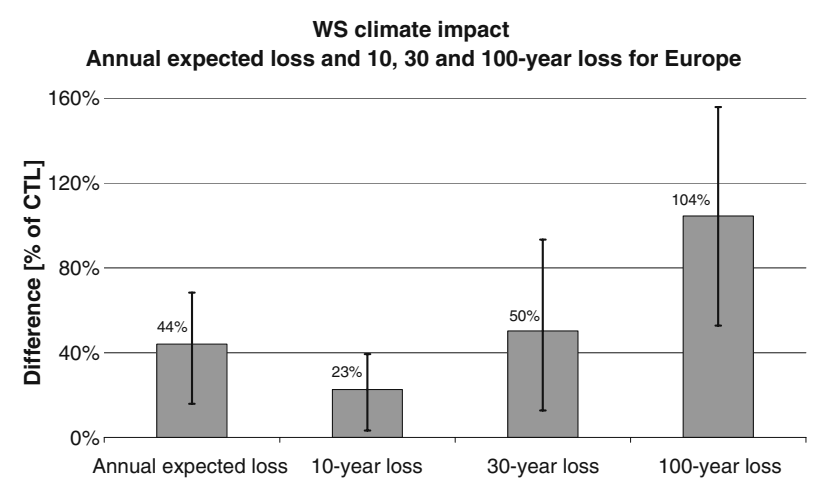

based on the mean values of the models used (Heck et al. 2006). Currently, the AEL burden from winter storms in Europe is about EUR 2.6 billion. Assuming linear progression, this figure could increase by around EUR 11 million annually. At first glance, the rise may not seem all that dramatic, particularly since all models have some element of uncertainty, and natural variability will confuse the signal of the underlying trend. However, this means that if claims were to increase by EUR 110 million, or almost five percent of today's levels within ten years, the expected annual insured loss from winter storms in Europe would be EUR 3.5 billion in 2085. That is EUR 0.9 billion more than at present. Similarly, for the highest layer in Fig. 9, the current 100-year loss for Europe of EUR 21 billion, the results suggest an annual increase of almost EUR 200 million, leading to a rise of EUR 2 billion in ten years (a 10\% increase compared to current loss levels).

The AEL for some of the national portfolios are summarized in Fig. 10. Most European countries show a considerable increase in AEL, but the climate change impacts differs from country to country (between $-23 \%$ and $+116 \%$ ). Consistent with our analysis in Figs. 7 and 8, there is an expected reduction in AEL for Ireland, parts of Scandinavia and parts of the Mediterranean region. Large regional variations exist in the mean and the spread, such that the deviations from the European mean (Fig. 9) can be substantial in individual countries. The highest impact is found for Denmark and Germany (labeled DNK and DEU in Fig. 10), which both are situated within the band of strongest gust increase over the North Sea (cf. Figs. 7 and 8).

Fig. 10 Regional climate change impact on annual expected losses for selected regional market portfolios. Mean increases (red bars) and uncertainties (i.e. spread) of the three different coupled model results

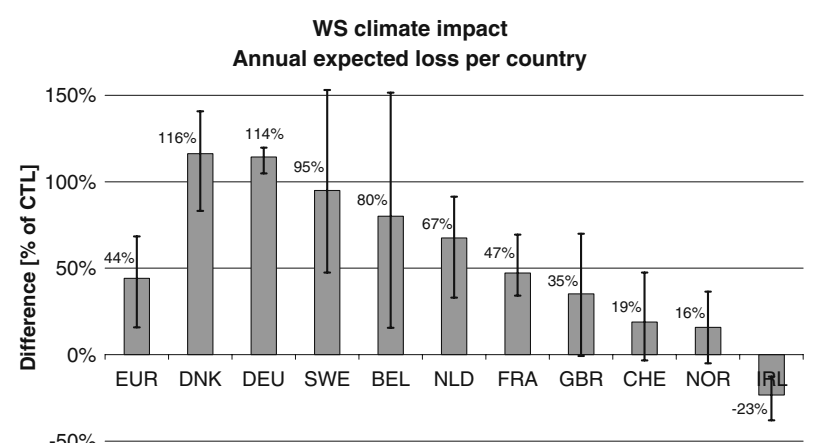

$-50 \%$ 
The models agree best for Germany, while for Denmark the spread is slightly higher. France shows the closest correspondence to the European mean, with a moderate spread. Larger uncertainties are found for Belgium and Sweden, but all models still predict an increase. In Great Britain the wind change has opposite signs for the northern and southern parts of the country in some models, but uniformly positive in others (cf. Section 4.3 and Fig. 8), which explains the huge spread and renders the mean loss-increase non-significant. Finally, Switzerland, Norway and in particular Ireland show a potential for a reduced AEL climate change impact, i.e. a decrease in storm damage, but the results are still not conclusive.

A comparison with the spatial patterns of the return period wind fields (Fig. 8) and the patterns of the frequency change of gust events (not shown) reveals close similarities, and hence it can be concluded that the observed climate change impact on the losses is a combined effect of changes in storm intensity as well as frequency.

\section{Discussion}

\subsection{Comparison with previous studies}

Wind gusts When comparing the wind gust fields simulated by similar coupled GCM-RCM model chains, several interesting similarities and differences exist. Consistent with previous publications (Leckebusch et al. 2006) we find a good correspondence of the amplitudes and wind patterns of the RCM control runs with downscaled ERA40 data and observations. ECHAM5 (HC) only slightly over(under-)estimate the ERA40-CHRM gust speed (Figs. 5, 6).

Downscaling and the use of sophisticated gust parametrizations is instrumental in reproducing high gusts amplitudes, especially in the upper tail of the distribution (Rockel and Woth 2007). Compare for instance the 50\% increase (larger over land) in gust amplitude of the 98\% quantile between the ECHAM5 (Pinto et al. (2007), their Fig. 3c) and the CHRM gusts downscaled from the same global model (Fig. 6a, 2nd row). In a comparable, but different GCM-RCM ensemble, Leckebusch et al. (2006) find that the HC-CHRM, as their only model with a gust parametrization, performs best in mimicking (even slightly overestimating) gust observations, especially for the high quantiles.

Uncertainties introduced into RCM simulations by emission scenarios and boundary conditions have been found to exceed the variability between different RCMs (Leckebusch et al. 2006; Déqué et al. 2007). Our results support these findings, a stronger variability of the wind fields with different GCMs is observed, than between different RCMs using the same global model (cf. Fig. 6).

In terms of the gust changes predicted under the A2 scenario, the coherent picture emerges that the increase in gust frequency and amplitude is overproportionally large for the upper quantiles of the distribution. This is linked to an increased storm track of intense events over central Europe (southern UK, Northern Germany and Denmark) and decreased occurrence over the Mediterranean and Scandinavia. These areas are consistently found in both GCM and coupled GCM-RCM studies. Quantitatively, climate change signals for the 98\% quantile of ECHAM5 winds (Pinto et al. (2007), Fig. 5f-h) range between $-1.2 \mathrm{~m} / \mathrm{s}$ and $+0.9 \mathrm{~m} / \mathrm{s}$, which is somewhat smaller than the range derived in our Figs. 7 and $8(-2.4 \mathrm{~m} / \mathrm{s}$ to $+1.4 \mathrm{~m} / \mathrm{s})$, 
probably due to the reasons mentioned above. A fairer comparison can be undertaken with Leckebusch et al. (2006), cf. their Figs. 6 and 7, who find up 2-4\% increase in the $99 \%$ quantile intensity and $25-50 \%$ increase in frequency with their set of RCM-models. This corresponds very well to the $\sim 3-5 \%$ increase in our simulations for the $98 \%$ quantile intensity.

These results are also in line with the earlier studies mentioned in the introduction. However it should be noted that the uncertainties associated with rare events are still largely unknown, and the model spread could be strongly underestimated.

Insurance loss A quantitative comparison for the climate change impact on insurance loss is hampered by the fact that projected insured losses derived from a coupled climate-damage model have not been published previously in the open literature.

A qualitative comparison can be undertaken with the loss potentials derived in Pinto et al. (2007) and Leckebusch et al. (2007) for GCM wind gusts, which, as mentioned before, estimate a wind-damage relation following Klawa and Ulbrich (2003). Our results would correspond to their "no-adaptation" case under the A2 scenario, however, they consider changes for all events, whereas we use the probabilistic approach to estimate changes in different frequency layers, which makes the studies difficult to compare.

The general characteristics of the losses are similar to the ones stated for the wind, i.e. areas affected, largest changes for highest wind speeds (or rarest events, Figs. 9, $10)$, hence qualitatively, the studies agree very well. The increased loss potentials are linked with enhanced values for the high percentiles of surface wind maxima over Western and Central Europe, which in turn are associated with an enhanced number and increased intensity of extreme cyclones over the British Isles and the North Sea (Pinto et al. 2007).

Leckebusch et al. (2007) focus on loss potentials for Germany and the UK, and their 4-member GCM ensemble yields an increase of $+21 \%$ and $+37 \%$, respectively. Although we cannot quantitatively compare the loss ratios due to different methodologies, this is partly contrary to our results, where Germany accounts for much more future losses than the UK (cf. Fig. 10). It is interesting that the inter-annual (not inter-model) variability range is much higher for the UK than for Germany, indicating a much broader loss distribution in the UK for the future climate (more extreme high- or low-loss events). Possibly, the larger inter-model variations for the UK-AEL in Fig. 10 is an expression of this. Also the disproportionate intensification of the minima and maxima for the rarer event gust fields could support that (Fig. 8), and the projected zero-wind line cutting across the UK might be one reason for the large variability in the projections.

In Pinto et al. (2007) 3 different realisations of the same GCM (ECHAM5) are used for the loss estimation, and applied to 4 different European regions. They estimate that the climate change impact on losses over the 100 years is largest for Germany $(+49 \%)$ and France $(+44 \%)$, followed by the non-significant changes observed for the UK $(+24 \%)$, Sweden/Norway $(+10 \%)$ and Portugal/Spain $(-5 \%)$. The order of our regional AEL is somewhat similar, but differs in that Sweden might experience quite a large increase, whereas there is no significant change detected for Norway. Pinto et al. (2007) also determine a significantly increased inter-annual variance for all the countries experiencing a loss increase, which corresponds to a reduction of return periods for extreme events, and this agrees well with our results. 
In conclusion, it can be argued that although a direct comparison of absolute loss values is difficult, the tendency for the regional impact bears some similarity. More importantly, despite the completely different approaches, a consistent change to the loss distribution is projected under climate change, with increased variability at the upper tail, and an expected reduction of return periods for the countries affected by the shifting storm track.

\subsection{Caveats and limitations}

A primary prerequisite for this study was to achieve a dynamically meaningful coupling of the climate models with the insurance model, while applying the simplestpossible method. This is a very pragmatic approach which is likely to be prone to a number of shortcomings. Other caveats arise from assumptions and uncertainties associated with each step of the methodology. These limitations are discussed in detail below.

In this study a small ensemble of climate model simulations has been used, and it has become evident from our analysis that the application of a multi-model ensemble on all scales considered is vital to obtain an estimate of the model uncertainty and significance of the results. Global-to-regional model chains incorporate a number of errors and uncertainties, which together amount to the forecast uncertainty (e.g., IPCC 2001; Schwierz et al. 2006). In general these include: emission scenario uncertainties (not considered here), uncertainties arising from the chaotic nature of the coupled atmosphere/ocean system, imperfect knowledge of the initial and boundary conditions; and errors in the imperfect numerical representation of dynamical and physical processes. The multi-model ensemble considered in this study is very small, and it is likely that the uncertainties are considerably larger than suggested by the error bars provided. Indeed, the driving atmospheric GCMs produce rather similar circulation changes over the European continent, and consideration of all available GCMs would yield a larger spread. Nevertheless, it is worth pointing out that the two GCMs considered are among the best when evaluated regarding their ability to represent synoptic-scale circulation types under current climatic conditions (van Ulden and van Oldenborgh 2006).

Similarly it can be argued that additional RCMs should be included in the analysis, in order to better represent the downscaling uncertainties, in particular as we have to rely on parameterizations of wind gusts. Here problems arise from uncertainties in the formulations of turbulence and boundary layer processes, as well as from the limited spatial resolution available and the use of a smoothed representation of the surface topography. However, our choice has been objective in the sense that we have used all RCM simulations available that were equipped with an advanced gust parameterization. Furthermore, the similarity of the CLM and CHRM results (despite using two models with a completely different dynamical core-one being hydrostatic the other non-hydrostatic) suggests that the uncertainties on the GCMscale dominate for the current application over those on the RCM-scale.

Although the performance of our straight-forward selection criterion for eventdays has been critically and successfully tested with reanalysis data, there is potential room for improvement. We focussed on land-points and their selection depends on the accuracy and resolution of the land-sea mask. It would also be interesting to include sea points close to the coastline in a future extension of this model. A more 
detailed analysis of the selected events also revealed a tendency in some models (especially CLM) to exceed the threshold criterion near elevated topography. It is therefore possible that some days are part of the selection that might not be related to the occurrence of a major storm event. It was not feasible to quantify this uncertainty within the scope of this study. Similarly, the calibration procedure employed when coupling to the insurance model is rather ad-hoc (a simple multiplicative adjustment) and more sophisticated approaches for adjusting the gust distributions are conceivable. However, the inter-model consistency and the comparability with other studies (see below) lends confidence in the results presented here.

Our estimates for long return periods were based upon the probabilistic generation of a large event set, which in effect represents a much longer time slice than directly available from the simulations. The result of this methodology depends crucially on the quality of the input wind data and the accuracy/validity of the statistical and/or dynamical assumptions underlying the probabilistic approach. A particular uncertainty arises from unknown, potentially drastic, future changes, because these are neither represented in the historic data, nor are the grounds available for their parametrization in the stochastic method. Therefore such a change cannot be mimicked easily in the probabilistic event set. In the same vein, the simulation period of 30 years underlying this study can still be considered short for tackling rare major loss events. It is planned that some longer high-resolution climate integrations will become available with the ongoing ENSEMBLE project. This project will provide extended (100 years) integrations at a spatial resolution of $25 \mathrm{~km}$.

Finally, some simplifications and uncertainties associated with the insurance model may have an impact on the predicted loss estimates. First, the accuracy of the results (and in particular the geographical distribution of the damages) is limited by the spatial resolution of the insurance model and the quality of the national market portfolios. In contrast to the operational insurance model, the version used in this study has been simplified regarding the vulnerability functions. An averaged vulnerability function is used for all risk types and does not allow for a distribution around the mean damage ratio. Uncertainties in the market portfolio also influence the final results. Upgrading the simplified loss-frequency curve and relaxing the restriction to proprietary losses could in principle add to a more accurate estimate of the climate change impacts. Second, the study concentrated only on changes from wind exposure. To consider the complete impact on insured losses, it would also be necessary to account for additional factors such as inflation, the increased concentration of insured values, higher insurance penetration, and protection and prevention measures. Also, this study did not estimate the impact of climate change on wind-related flood and storm-surge risks.

\subsection{Outlook}

In future research, our European winter storm loss results could be explored further and the developed methodology and strategy may be further utilized and adapted to investigate additional aspects of anthropogenic climate change, which would be of interest both from scientific and socio-economic perspectives. Specific applications and extensions include:

- The uncertainties of the climate simulations need to be addressed and quantified more carefully. Ideally, the multi-scale, multi-model climate ensemble should 
contain more models, use higher resolution and span a longer time period. This would also help to better estimate trends in extremes with high return periods, and provide an assessment of the expected transience in wind damages (beyond considering time slices as in the current study). Such a computationally expensive task can only be carried out in a consortium effort, as currently underway within the ENSEMBLES project (see http://www.ensembles-eu.org/).

- It might also be interesting to couple wind data to insurance models on shorter, seasonal-to-decadal time-scales. Such an attempt is undertaken in a follow-on study (Della-Marta et al. 2009).

- The ensemble approach could be extended to include an ensemble of different insurance loss models. These may account for differences in market portfolios and wind-damage relationships. Several loss models are in use within the insurance industry, but these are usually not made available for research purposes.

- Coupled climate-damage models might also be used to assess the role of changes in loss burden, decisions by stakeholders and policy makers, and impacts of mitigation and adaptation strategies.

- As suggested by Pielke et al. (1999) it is desirable to determine the skill of the coupled climate-damage model chain and quantitatively assess its predictive capabilities. This is however currently hampered by the difficulty of generating a comprehensive baseline model from historic loss data. The baseline model would serve as the "climatology" against which the skill of the model chain needs to be evaluated.

- The strategy developed in the current study could be extended to undertake sensitivity studies with respect to a wider range of insurance portfolios. The insured value distributions and contract conditions also depend on the specific reinsurer and change significantly with time. Detailed sensitivity studies are fundamental to disentangle and quantify the relative contributions of climate changes in comparison with temporal variations in portfolio and contract conditions.

\section{Summary and conclusions}

Our study has explored for the first time the coupling of a regional multi-model climate ensemble to a probabilistic operational insurance model. It produced dynamically meaningful and economically viable estimates of expected changes to insured losses and return periods on the European scale, with regional resolution.

The main findings of this study are:

- Mean gusts of the CTL runs correspond very well to the downscaled ERA40verification (Figs. 5, 6), and the magnitudes are 2-3 times higher than in a GCM alone. Downscaling is thought to be important since a small improvement in the quality of wind data can dramatically increase the accuracy of the damage model (Watson and Johnson 2004), and the sensitivity of the insurance model's vulnerability function to the wind speed is extremely large.

- Changing the driving GCM has more impact on the spread of the ensemble gust speeds than different versions of regional models (Fig. 6). This might be partly caused by the fact that both RCMs use the same gust parametrization. Hence the regional model variability might still be underestimated. 
- Projected climate change of wind gusts are consistent within the small ensemble, both in terms of pattern and amplitude (Fig. 7). Consistent with existing studies, the strength of the extreme storms are expected to increase in a band across central Europe (southern UK, German bight, northern Germany, and into eastern Europe). The increase is stronger for the rarer events. Wind gusts of storms decrease over northern Scandinavia and Southern Europe and the Mediterranean.

- The probabilistic derivation of the climate change impact offers the novel possibility to estimate return periods of insured losses from climate change scenarios. The changes in the patterns of the 10-, 30-, and 100-year storm gusts (Fig. 8) and the wind climatologies (Fig. 7) closely correspond. The rare events show the largest climate change impact, but are also beset with the largest uncertainties (see below). Most intra-ensemble variability is observed for Ireland and the UK, the Mediterranean, and parts of Eastern Europe.

- The resulting changes on losses over the 110 -year period considered are positive for all layers and all model runs considered (Fig. 9 and Table 2). A mean increase of 44\% (annual expected loss); 23\% (10 years loss); 50\% (30 years loss); 104\% (100 years loss) for Europe ensues. Also there is a disproportionate increase in losses for rare, extreme events. The changes result from both, an increase in severity and frequency of the selected storm events.

- A large country-to-country variability of the expected losses exists (Fig. 10), due to the combination of the spatially inhomogeneous portfolio and the horizontal variability of the gust change. Denmark and Germany experience the largest relative loss increases (116\% and $114 \%$, respectively, with small inter-model variability), whereas Ireland shows a negative mean climate change impact. The changes for the UK, Switzerland and Norway are positive, but still inconclusive due to high ensemble variability.

Rare events In the introduction we have discussed (see Fig. 1) that single events dominate the yearly loss amounts caused by European winter storms. This property implies intrinsic difficulties in the detection of damage trends, be it in the past or future. Hence the impact of climate change on winter storms is difficult to detect in statistical terms, as the underlying trend will be distorted by rare, randomly occurring events, or by the fortuitous absence of catastrophic events. Indeed, a systematic analysis of the issue shows that the probability to detect trends of rare events decreases with the size of the event (Frei and Schär 2001). Thus, the chances to detect the projected trend in wind storms are highest for moderate events, while the expected impacts in terms of damages are highest in the category of extremely rare exceptional events. This highlights a difficult dilemma, and suggests that the course of wind damages in Europe for the next decades will likely remain to be dominated by rare events and interannual variability.

Socio-economic implications Although there is evidence for a positive trend in European wind storm losses from our study, it is likely that no clear trend will be detectable with significance in the next few years, and indeed a great challenge will be avoiding a false sense of security. Some statements for policy makers and stakeholders arise. 
Today's economy would not function without effective and efficient mechanisms to transfer risk. Insurers and reinsurers play a key role in this process. In order for the sector to remain a reliable risk taker in future, changes in the risk landscape have to be identified and communicated at an early stage. In order to write business sustainably, impacts of climate change have to be systematically integrated into the risk assessment and management processes of the insurance industry. The risk premium which is the basis for the insurance premium, must reflect the changes in exposure, and the increased risk must be reflected in capital and capacity steering models.

Underwriting adjustments are however only part of the solution. An optimal outcome is achievable only through devoting significant effort to mitigate the impact of natural catastrophes. It is in the interest of all stakeholders, including insurers to create incentives for clients to implement protective changes and structural modifications for their properties. Preventive building maintenance can considerably reduce storm damage.

In conclusion, it should be noted that while the insurance industry is an important contributor, the climate question cannot be answered by one stakeholder group alone. It needs the participation of all relevant societal, political and economic stakeholders. New, sustainable and effective protection measures need to be taken, to reduce the loss burden, including those that involve politics and society. These measures range from global climate protection, with the reduction of greenhouse gas emissions, cutting back on energy consumption, and the development of new, environmentally friendly technologies; to mitigation and to the adaptation to extreme events. Examples are the protection of objects, including constructive measures, appropriate land-use planning and construction standards, risk and catastrophe management (early warning systems). It is only through combined efforts that the challenges of climate change can be met adequately.

The technique introduced in this study and its application to realistic market portfolios offer exciting prospects for future research on the impact of climate change that is relevant for policy makers, scientists and economists.

Acknowledgements Parts of the data have been provided through the PRUDENCE data archive, funded by the EU through contract EVK2-CT2001-00132. We are particularly indebted to Jens H. Christensen and his colleagues for setting up the PRUDENCE data server, and to Burkhardt Rockel for providing the CLM simulations. Access to ERA40 data has kindly been provided by MeteoSwiss. Additional funding was provided by the Swiss National Science Foundation through the Swiss NCCR Climate Program, by the EU project ENSEMBLES, and by Swiss Re. The model simulations of ETH have been conducted at the Swiss Center for Scientific Computing (CSCS).

\section{References}

Beersma JJ, Rider KM, Komen GJ, Kaas E, Kharin VV (1993) An analysis of extra-tropical storms in the North Atlantic region as simulated in a control and $2 \mathrm{xCO}_{2}$ time-slice experiment with a high-resolution atmospheric model. Tellus A49(3):347-361

Berz GA (1993) Global warming and the insurance industry. Interdiscip Sci Rev 18(2):120-125

Boer GJ (1995) Some dynamical consequences of greenhouse gas warming. Atmos Ocean 33(4): $731-751$

Carnell RE, Senior CA (1998) Changes in mid-latitude variability due to increasing greenhouse gases and sulfate aerosols. Clim Dyn 14:369-383 
Changnon SA, Changnon D, Fosse ER, Hoganson DC, Roth RJ, Totsch JM (1997) Effects of recent weather extremes on the insurance industry: major implications for the atmospheric sciences. Bull Am Meteorol Soc 78(3):425-435

Christensen JH, Christensen OB (2007) A summary of the PRUDENCE model projects of changes in European climate by the end of this century. Clim Change 81(Suppl 1):7-30. doi:10.1007/ s10584-006-9210-7

Christensen JH, Carter TR, Giorgi F (2002) Prudence employs new methods to assess European climate change. E O S 83:147

Davies HC (1976) Lateral boundary formulation for multilevel prediction models. Q J R Meteorol Soc 102(432):405-418

DelGenio AD, Lacis AA, Ruedy RA (1991) Simulations of the effect of a warmer climate on atmospheric humidity. Nature 351(6325):382-385

Della-Marta P, Liniger MA, Appenzeller C, Bresch DN, Köllner-Heck P, Muccione V (2009) Improved estimates of the European winter wind storm climate and the risk of reinsurance loss using climate model data. JAMC (in press)

Déqué M, Rowell DP, Lüthi D, Giorgi F, Christensen JH, Rockel B, Jacob D, Kjellstroem E, de Castro M, van den Hurk BJJM (2007) An intercomparison of regional climate simulations for Europe: assessing uncertainties in model projections. Clim Change 81(Suppl 1):53-70. doi:10.1007/s10584-006-9228-x

Frei C, Schär C (2001) Detection probability of trends in rare events: theory and application to heavy precipitation in the Alpine region. J Climate 14:1568-1584

Geng QZ, Sugi M (2003) Possible change of extratropical cyclone activity due to enhanced greenhouse gases and sulfate aerosols-Study with a high-resolution AGCM. J Climate 16:22622274

Heck P, Bresch DN, Tröber S (2006) The effects of climate change: storm damage in europe on the rise. Swiss Re Focus Report. http://www.swissre.com/

Held IM (1993) Large-scale dynamics and global warming. Bull Amer Meteor Soc 74(2):228-241

Hoskins BJ, McIntyre ME, Robertson AW (1985) On the use and significance of isentropic potential vorticity maps. Q J R Meteorol Soc 111:877-946

IPCC (2001) Climate change. The scientific bases. Cambridge University Press, Cambridge, 881 pp

IPCC (2007) Climate change. The physical science basis. http://www.ipcc.ch

Johns TC, Gregory JM, Ingram WJ, Johnson CE, Jones A, Lowe JA, Mitchell JFB, Roberts DL, Sexton DM, Stevenson DS, Tett SFB, Woodage MJ (2003) Anthropogenic climate change for 1860 to 2100 simulated with the HadCM3 model under updated emissions scenarios. Clim Dynamics 20:583-612

Kessler E (1969) On the distribution and continuity of water substance in atmospheric circulations. Meteorol Monogr AMS 32:84

Klawa M, Ulbrich U (2003) A model for the estimation of storm losses and the identification of severe winter storms in Germany. Nat Hazards Earth Syst Sci 3:725-732

Knippertz P, Ulbrich U, Speth P (2000) Changing cyclones and surface wind speeds over the North Atlantic and Europe in a transient GHG experiment. Clim Res 15(2):109-122

Lamb HH, Fydendahl K (1991) Grading of storms. In: Historic storms of the North Sea, British Isles and Northwest Europe. Cambridge University Press, Cambridge, 204 pp, 7-32

Lambert SJ (1995) The effects of enhanced greenhouse warming on winter cyclone frequencies and strengths. J Climate 8:1447-1452

Leckebusch GC, Ulbrich U (2004) On the relationship between cyclones and extreme windstorm events over Europe under climate change. Glob Planet Change 44(1-4):181-193

Leckebusch GC, Koffi B, Ulbrich U, Pinto JG, Spangehl T, Zacharias S (2006) Analysis of frequency and intensity of European winter storm events from a multi-model perspective, at synoptic and regional scales. Clim Res 31:59-74

Leckebusch GC, Ulbrich U, Fröhlich L, Pinto J (2007) Property loss potentials for European midlatitude storms in a changing climate. Geophys Res Lett 34:L05703. doi:10.1029/2006GL027663

Lin Y-L, Farley RD, Orville HD (1983) Bulk parametrization of the snow field in a cloud model. J Appl Meteor 22(6):1065-1092

Lüthi D, Cress A, Frei C, Schär C (1996) Interannual variability and regional climate simulations. Theor Appl Climatol 53:85-209

Majewski D (1991) Numerical methods in atmospheric models. ECMWF SEM NUM METH A 2:147-191

Pielke RA Jr, Landsea CW, Musulin RT, Downton M (1999) Evaluation of catastrophe models using a normalized historical record. Why it is needed and how to do it. J Insur Regul 18(2):177-194 
Pinto J, Fröhlich EL, Leckebusch GC, Ulbrich U (2007) Changing European storm loss potentials under modified climate conditions according to ensemble simulations of the ECHAM5/MPIOM1 GCM. Nat Hazards Earth Syst Sci 7:165-175

Pope DV, Gallani M, Rowntree R, Stratton A (2000) The impact of new physical parameterizations in the Hadley Centre climate model HadAM3. Clim Dyn 16:123-146

Raible CC, Saaroni H, Ziv B, Wild M (2009) Winter synoptic-scale variability over the Mediterranean Basin under future climate conditions as simulated by the ECHAM5. Clim Dyn (available online). doi:10.1007/s00382-009-0678-5

Rockel B, Woth K (2007) Future changes in near surface wind speed extremes over Europe from an ensemble of RCM simulations. Clim Change 81(Suppl 1):267-280. doi:10.1007/ s10584-006-9227-y

Roeckner E, Bäuml G, Bonaventura L, Brokopf R, Esch M, Giorgetta M, Hagemann S, Kirchner I, Kornblueh L, Manzini E, Rhodin A, Schlese U, Schulzweida U, Tompkins A (2003) The atmospheric general circulation model ECHAM5. Part I: model description. Max Planck Institute for Meteorology Rep. 349, 127pp. www.mpimet.mpg.de

Roeckner E, Brokopf R, Esch M, Giorgetta M, Hagemann S, Kornblueh L, Manzini E, Schlese U, Schulzweida U (2006) Sensitivity of simulated climate to horizontal and vertical resolution in the ECHAM5 atmosphere model. J Climate 19(16):3771-3791

Schär C, Vidale PL, Lüthi D, Frei C, Häberli C, Liniger M, Appenzeller C (2004) The role of increasing temperature variability in European summer heat waves. Nature 427:332-336

Schrodin R (ed) (1995) Dokumentation des EM/DM Systems. Deutscher Wetterdienst, Offenbach a. Main

Schubert M, Perlwitz J, Blender R, Fraedrich K, Lunkeit F (1998) North Atlantic cyclones in CO2induced warm climate simulations: frequency, intensity, and tracks. Clim Dyn 14:827-837

Schwierz C, Appenzeller C, Davies H, Liniger M, Müller W, Stocker T, Yoshimori M (2006) Challenges posed by and approaches to the study of seasonal-to-decadal climate variability. Clim Change 79(1-2):31-63

Steppeler J, Doms G, Schättler U, Bitzer HW, Gassmann A, Damrath U, Gregoric G (2003) Mesogamma scale forecasts using the nonhydrostatic model LM. Meteorol Atmos Phys 82:75-96

Tiedtke M (1989) A comprehensive mass flux scheme for cumulus parametrization in large-scale models. Mon Weather Rev 117(8):1779-1800

Ulbrich U, Christoph M (1999) A shift of the NAO and increasing storm track activity over Europe due to anthropogenic greenhouse gas forcing. Clim Dyn 15:551-559

Uppala SM, Kållberg PW, Simmons AJ, Andrae U, da Costa Bechtold V, Fiorino M, Gibson JK, Haseler J, Hernandez A, Kelly GA, Li X, Onogi K, Saarinen S, Sokka N, Allan RP, Andersson E, Arpe K, Balmaseda MA, Beljaars ACM, van de Berg L, Bidlot J, Bormann N, Caires S, Chevallier F, Dethof A, Dragosavac M, Fisher M, Fuentes M, Hagemann S, Hlm E, Hoskins BJ, Isaksen L, Janssen PAEM, Jenne R, McNally AP, Mahfouf J-F, Morcrette J-J, Rayner NA, Saunders RW, Simon P, Sterl A, Trenberth KE, Untch A, Vasiljevic D, Viterbo P, Woollen J (2005) The ERA-40 re-analysis. Q J R Meteorol Soc 131:2961-3012. doi:10.1256/qj.04.176

Van Ulden AO, van Oldenborgh GJ (2006) Large-scale atmospheric circulation biases and changes in global climate simulations and their importance for climate change in Central Europe. Atmos Chem Phys 6:863-881

Vidale PL, Lüthi D, Frei C, Seneviratne S, Schär C (2003) Predictability and uncertainty in a regional climate model. J Geophys Res 108(D18):Art. No. 4586

Vidale PL, Lüthi D, Wegmann R, Schär C (2007) European summer climate variability in a heterogeneous multi-model ensemble. Clim Change 81(Suppl 1):209-232. doi:10.1007/s10584-006-9218-Z

Watson CC, Johnson ME (2004) Hurricane loss estimation models: opportunities for improving the State of the Art. Bull Amer Meteor Soc 85(11):1713

Wernli H, Dirren S, Liniger MA, Zillig M (2002) Dynamical aspects of the life cycle of the winter storm 'Lothar' (24-26 December 1999). Q J R Meteor Soc 128(580):405-429

Woth K, Weisse R, von Storch H (2006) Climate change and North Sea storm surge extremes: an ensemble study of storm surge extremes expected in a changed climate projected by four different regional climate models. Ocean Dyn 56(1):3-15

Zecchetto S, Cappa C (2001) The spatial structure of the Mediterranean Sea winds revealed by ERSscatterometer. Int J Remote Sens 22(1):45-70. doi:10.1080/014311601750038848

Zimmerli R et al (2003) Natural catastrophes and reinsurance. Swiss Reinsurance company publication. http://www.swissre.com/ 